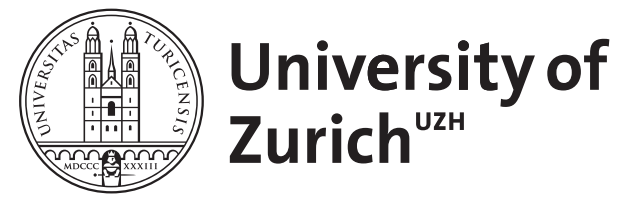

Zurich Open Repository and Archive

University of Zurich

University Library

Strickhofstrasse 39

CH-8057 Zurich

www.zora.uzh.ch

Year: 2019

Die staatliche Blockierung des Zugangs zu Internetinhalten in Russland Eine Analyse aus verfassungsrechtlicher Sicht

\author{
Beriger, Julian-Ivan
}

Posted at the Zurich Open Repository and Archive, University of Zurich

ZORA URL: https://doi.org/10.5167/uzh-173214

Journal Article

Published Version

Originally published at:

Beriger, Julian-Ivan (2019). Die staatliche Blockierung des Zugangs zu Internetinhalten in Russland Eine Analyse aus verfassungsrechtlicher Sicht. Osteuropa-Recht, 65(1):5-36. 


\section{osteuropa \\ recht}

Fragen zur Rechtsentwicklung

in Mittel- und Osteuropa sowie den GUS-Staaten

65. Jahrgang, Heft $1 \mid 2019$

„Staat und Medien“"

EDITORIAL

\section{AUFSÄTZE}

Julian-Ivan Beriger

Die staatliche Blockierung des Zugangs zu Internetinhalten in Russland -

Eine Analyse aus verfassungsrechtlicher Sicht

Zoya Mylovanova, Kseniya Ostrovska

Mass and Social Media in Ukraine: Between Chaos and Media Capture

\section{Gábor Polyák}

Ökonomische Bedeutung und rechtlicher Rahmen der staatlichen Werbung in der ungarischen Medienpolitik

Bernd Wieser

Verfassungsänderung und Normenkontrolle in der Ukraine

Sergey A. Markuntsov, Martin Paul Waßmer

Die Einführung der strafrechtlichen Verantwortlichkeit juristischer Personen in Russland

Benedikt Harzl, Aistè Mickonytè

Armenia Caught Between (In-)Compatible Legal Orders: Paths of Competitive and Cumulative Integration

\section{AUS DER FORSCHUNG}

$15^{\text {th }}$ International Students Seminar (ISS) "Right to Vote and Electoral Law in Comparative Perspective", Kenyatta School of Law, 4.-9.2.2019 (Anna Börger), S. 135 


\section{AUS DEM SCHRIFTTUM}

Rainer Birke/Rainer Wedde (Hrsg.) Im Dienst des deutsch-russischen Rechtsdialogs, 30 Jahre Deutsch-Russische Juristenvereinigung (Carmen Schmidt), S. 137; O.V. Sovgyrja/N.G. Šuklina Konstytucijne pravo Ukrajiny (Verfassungsrecht der Ukraine) (Bernd Wieser), S. 138

\section{AUS JUSTIZ UND RECHTSPRECHUNG IN OSTEUROPA}

UNGARN: Verfassungsgerichtsurteil 13/2018. (IX. 4.) AB über die Verfassungswidrigkeit unkontrollierter Grundwasserentnahmen, S. 141 (Herbert Küpper); Verfassungsgerichtsurteil 14/2018. (IX. 27.) AB über den Umfang verwaltungsgerichtlicher Kontrolle, S. 142 (Herbert Küpper)

\section{AUS DER RECHTSPRECHUNG DES EGMR}

Konventionswidrigkeit der Verstaatlichung des Schulbuchvertriebs: Konventionswidrigkeit der Verstaatlichung des Schulbuchvertriebs, S. 143 (Herbert Küpper) 


\section{EDITORIAL}

Der Schwerpunkt dieses Hefts ist dem sich wandelnden Verhältnis zwischen Staat und Medien und dem zunehmenden Einfluss des Staates auf die Berichterstattung in den Medien in drei mittel- und osteuropäischen Staaten gewidmet. Eine unter rechtsstaatlichen Gesichtspunkten problematische Entwicklung ist dabei nicht allein bei den traditionellen Print- und audiovisuellen Medien zu beobachten; betroffen sind heute auch die sog. neuen Medien. Das komplexe rechtliche Instrumentarium, das in Russland in den letzten Jahren geschaffen wurde, um den Zugang des Bürgers zu Informationsressourcen zu beschränken, ist Gegenstand des ersten Beitrags von Julian-Ivan Beriger. Der Autor identifiziert als wichtigstes Instrument zwei Verfahren zur Sperrung von Internetinhalten, deren Normierung und aus verfassungsrechtlicher Sicht nicht immer unbedenkliche Anwendung im Einzelfall durch Behörden und Gerichte ausführlich besprochen werden. Zoya Mylovanova und Kseniya Ostrovska geben im Anschluss einen Überblick über die Lage im Mediensektor der Ukraine und die wichtigsten, hier eher herkömmlichen Instrumente der staatlichen Einflussnahme. Anlass zur Sorge geben vor allem Maßnahmen der Regierung zur Bekämpfung ,pro-russischer" bzw. ,anti-ukrainischer Propaganda“, sind Journalisten, Sender, Internetseiten, Plattformen, die als Sprachrohr Russlands verdächtigt werden, von Sanktionen - Verwarnung, Geldbuße, Lizenzentzug oder im Fall eines Ausländers Einreiseverbot - bedroht. Subtilere, aber nicht weniger wirksame Instrumente der Einflussnahme wurden nach Gábor Polyák in Ungarn ergriffen, indem durch Untergrabung der Unabhängigkeit der Aufsichtsorgane, durch Beschränkung des Zugangs zu Ressourcen, die zur Ausübung der Tätigkeit erforderlich sind, durch Kontrolle des Zugangs zu öffentlichen Informationen sowie vor allem auch mit Hilfe der staatlichen Werbung als Instrument der Medienfinanzierung versucht wird, eine regierungskritische Berichterstattung zu verhindern.

Die weiteren Beiträge sind unterschiedlichen Themen gewidmet. Bernd Wieser setzt sich, konzentriert auf Verfahren und Normenkontrolle, kritisch mit der Entwicklung der ukrainischen Verfassung von 1996 auseinander, die 2004 geändert, in ihrer geänderten Fassung 2010 vom Verfassungsgericht für verfassungswidrig erklärt, 2014 wieder in ihrer Fassung von 2004, 2011 und 2013 in Kraft gesetzt und 2016 erneut geändert wurde. Sergey Aleksandrovich Markuntsov und Paul Waßmer berichten über die aktuelle russische Debatte über das Pro und Contra einer strafrechtlichen Verantwortlichkeit juristischer Personen, die auch in Deutschland in jüngster Zeit wieder diskutiert wird. Über erste Gesetzesentwürfe sind diesbezügliche Bemühungen aber 
auch in Russland bisher nicht hinausgegangen. Benedikt Harzl und Aiste Mickonyte untersuchen schließlich die rechtlichen und politischen Herausforderungen, die Armenien mit einem Spagat zwischen Europa und Asien zu meistern hat, wird mit dem Abschluss von Freihandels- und Partnerschaftsabkommen einerseits die Integration in Europa, mit dem Beitritt zur Eurasischen Union und zum Vertrag über kollektive Sicherheit andererseits zugleich die enge Zusammenarbeit im Verbund ehemaliger Sowjetstaaten unter Führung Russlands angestrebt.

Wir wünschen eine interessante Lektüre! 
Julian-Ivan Beriger

\title{
Die staatliche Blockierung des Zugangs zu Internetinhalten in Russland - Eine Analyse aus verfassungsrechtlicher Sicht*
}

\author{
The State Blocking of Access to Online Content in Russia - \\ An Analysis from a Constitutional Point of View
}

\begin{abstract}
:
Since 2012, the legal possibilities for state blocking of web content in Russia have been largely expanded by amendments to the Federal Information Act (Art. 15.1.-15.8. Federal law of 27 July 2006 No. 149-FZ). Therefore, Internet censorship has been steadily growing in Russia over the last years. From a constitutional point of view, the "ordinary procedure" in Art. 15.1. InfoG and the "express block" in Art. 15.3. InfoG are the most important state blocking procedures. While in the "ordinary procedure" the owner of the website is given the opportunity to voluntarily delete the offending information, the "express block" suggests immediate blocking of the relevant websites by order of the Attorney General of the Russian Federation. The state blocking of online content affects the right to information and communication and the freedom of expression, guaranteed in Art. 29 of the Russian Constitution (Art. 10 ECHR and Art. 19 ICCPR). The current blocking practice of the Russian authorities does not meet the requirement of "proportionality" of state action, which is stated by Art. 55 (3) of the Russian Constitution (Art. 10 (2) ECHR and Art. 19 (2) ICCPR). Legal regulation of the internet is expected to continue growing in Russia due to the various legislative initiatives in this field.
\end{abstract}

\section{Einleitung}

Das Bedürfnis nach staatlicher Regulierung und Kontrolle von Internetinhalten nimmt mit fortschreitender Digitalisierung des Lebensalltags zu, die auch in Russland immer mehr Einzug hält. ${ }^{1}$ Die Möglichkeiten der staatlichen Regulierung des russischsprachigen Internetsegments (sog. ,Runet“) wurden in Russland seit 2012 gesetzgeberisch

* Beriger, Julian-Ivan, Dr. jur., Postdoktorand/Habilitand, Zentrum für Demokratie Aarau (ZDA)/c2 d, Rechtswissenschaftliches Institut, Universität Zürich, juristischer Mitarbeiter am Bundesverwaltungsgericht der Schweiz.

1 Im Jahr 2017 und Anfang 2018 betrug das aktive Internet-Publikum (pro 24 Stunden mindestens einmal online) in Russland 63,8 Prozent der Gesamtbevölkerung. Dazu die Studie des Fonds „Общественное мнение“ (.,Gesellschaftsmeinung“) vom 4. April 2018, https://fom.ru/SMI-i-internet/13999, 15.1.2019.

OER 1/2019, DOI: 10.5771/0030-6444-2019-1-5 
stark erweitert ${ }^{2}$ und ein Ende der Regulierungsflut ist derzeit nicht in Sicht. ${ }^{3}$ Bei internationalen Vergleichen der Internet- ${ }^{4}$ und Medienfreiheit ${ }^{5}$ schnitt Russland in den letzten Jahren immer schlechter ab. ${ }^{6}$

Auf Grundlage des Föderalen Gesetzes vom 27. Juli 2006 Nr. 149-FZ „über die Information, die Informationstechnologien und den Schutz von Information" (zit. InfoG $)^{7}$ hat sich in Russland ein komplexes rechtliches Instrumentarium zur staatlichen Einschränkung des Zugangs zu Informationsressourcen im Internet herausgebildet. Je nach Inhalt der beanstandeten Information kommen unterschiedliche Sperrverfahren zur Anwendung. ${ }^{8}$

Im vorliegenden Beitrag werden zwei Sperrverfahren untersucht, die in verfassungsrechtlicher Hinsicht besonders bedeutsam sind, und zwar die Sperre verbotener Online-Informationen nach Art. 15.1. InfoG (,ordentliches Verfahren“) und die „Eilsperre" in Art. 15.3. InfoG. Aktuell sind gegen die Sperrpraxis der russischen Behörden im Zusammenhang mit diesen beiden Verfahren zwei Beschwerden vor dem Europäischen Gerichtshof für Menschenrechte (EGMR) hängig.9

$2 \mathrm{Zu}$ den entsprechenden Änderungen in der Informationsgesetzgebung sogleich unter II.

3 Im Dezember 2018 wurde zuletzt der Gesetzesentwurf Nr. 469143-7 von I. Jarovaja und anderen Abgeordneten der Staatsduma angenommen, der die sofortige Blockierung des Zugangs zu Online-Inhalten fordert, in denen Kinder zu Selbstmord oder der Begehung von Verbrechen angehalten werden. Die Gesetzesänderung ist am 29. Dezember 2018 wirksam geworden (vgl. Art. 1 Федеральный закон (Ф3) от 18 декабря 2018 N 472-Ф3 „О внесении изменений в статью 15.1 Ф3 Об информации, информационных технологиях и о защите информации〉 и статью 5 ФЗ (О защите детей от информации, причиняющей вред их здоровью и развитию" ") (Föderales Gesetz (FG) vom 18. Dezember 2018 Nr. 472FZ, ,über die Änderung von Art. 15.1. InfoG und Art. 5 des Kindesschutzgesetzes"), C3 РФ 24.12.2018, N 52, ст. 8101 (SZRF 24.12.2018, Nr. 52, Pos. 8101) (zit. Änderungsgesetz Nr. 472-FZ).

4 Auf der Skala der Internetfreiheit von „Freedom House“ erzielte Russland 67 von 100 Punkten im Jahr 2018, weshalb das Internet als ,,unfrei“ qualifiziert wird. Vgl. https://freed omhouse.org/report/freedom-net/2018/russia, 15.1.2019.

5 Auf der Skala des Weltpressefreiheitsindex (World Press Freedom Index) befindet sich Russland im Jahr 2018 auf Platz 148 von 180, https://rsf.org/en/ranking/2017\#, 15.1.2019.

6 Vgl. „Country report Russia Freedom on the Net 2018“, https://freedomhouse.org/report/fre edom-net/2018/russia, 15.1.2019 (zit. Bericht Freedom House 2018).

7 Ф3 от 27 июля 2006 г. N 149-Ф3 „Об информации, информационных технологиях и о защите информации“" (FG vom 27. Juli 2006 Nr. 149-FZ, ,über die Information, die Informationstechnologien und den Schutz von Information"), С Р РФ 31.7.2006 N 31 (1 ч.), ст. 3448 (SZRF 31.7.2006, Nr. 31 (1 T.), Pos. 3448).

8 Man unterscheidet Verfahren im Zusammenhang (1.) mit verbotener Information (Art. 15.1. InfoG), (2.) Information, welche das Urheberrecht oder geistiges Eigentum verletzt (Art. 15.2. InfoG), (3.) gesetzeswidrig verbreiteter Information (Art. 15.3. InfoG), (4.) Informationsressourcen der Organisatoren der Verbreitung von Information (Art. 15.4. InfoG), (5.) Information, welche das Datenschutzrecht verletzt (Art. 15.5. InfoG) sowie (6.) Kopien gesperrter Internetressourcen (Art. 15.6 ${ }^{1}$ InfoG).

9 EGMR, Vladimir Vladimirovich Kharitonov v. Russia, application no. 10795/14, http:// hudoc.echr.coe.int/eng?i=001-173648, 15.1.2019; EGMR, OOO FLAVUS v. Russia and 4 other applications, no. 12468/15, http://hudoc.echr.coe.int/eng?i=001-177236, 15.1.2019. Zu den beiden Verfahren hinten III.4.b) und c) sowie V. 
Als Erstes wird überblicksartig auf die einschlägigen Rechtsgrundlagen eingegangen (II.), um in einem nächsten Schritt die beiden Sperrverfahren vergleichend zu untersuchen (III.). Danach werden einige verfassungsrechtliche Probleme identifiziert (IV.) und die Ergebnisse einer Würdigung unterzogen (V.).

\section{Rechtsgrundlagen}

\section{Föderale Ebene}

Bei der Regulierung von Rechtsbeziehungen im Informationsbereich stützt sich die Russische Föderation (im Folgenden: RF) auf Art. 71 Bst. „ ${ }^{\text {“ V VfRF, }}{ }^{10}$ wonach sich Fragen betreffend Information und Kommunikation in der ausschließlichen Kompetenz der RF befinden. ${ }^{11}$ Bei der Sperre von verbotenen Internetinhalten kommt subsidiär auch Art. 71 Bst. „B“ VfRF (Regulierung und Schutz der Rechte und Freiheiten des Menschen und Bürgers) als Verfassungsgrundlage in Betracht. ${ }^{12}$ Daneben sind je nach Inhalt der $\mathrm{zu}$ sperrenden Information auch spezielle Verfassungsgrundlagen denkbar, so z. B. Art. 13 Abs. 5 VfRF im Zusammenhang mit der Sperre extremistischer Materialien.

Zentrale gesetzliche Grundlage zur staatlichen Regulierung von Informationsbeziehungen in der RF ist das InfoG (vgl. den weiten Anwendungsbereich in Art. 1 Abs. 1 InfoG). ${ }^{13}$ Die weitreichenden Möglichkeiten zur staatlichen Einschränkung des Zugangs zu Online-Informationsressourcen wurden durch nachträgliche Änderungen des InfoG ab 2012 eingeführt (vgl. Art. 15.1.-15.8. InfoG). ${ }^{14}$ Die hier in Frage stehen-

10 Конституция Российской Федерации, принята всенародным голосованием 12 декабря 1993 г. (Verfassung der RF, angenommen in der Volksabstimmung vom 12. Dezember 1993), C3 РФ 4.8.2014 N 31, ст. 4398 (SZRF 4.8.2014, Nr. 31, Pos. 4398) (zit. VfRF).

11 П.У. Кузнецов, Информационное право (Kuznecov, Informationsrecht), Moskau 2017, S. $123 ;$ Я.В. Кудашкин, Административно-правовое регулириование отношений в сети интернет в РФ (Kudaškin, Verwaltungsrechtliche Regulierung der Beziehungen im Internet in der RF), Saransk 2012, S. 99.

12 С.М. Казанчев, ст. 29 VfRF, in: В.Д. Зорькин (ред.), Комментарий к Конституции Российской Федерации (Kazancev, Art. 29 VfRF, in: Zor'kin (Red.), Kommentar zur Verfassung der RF), 3. Aufl., Moskau 2013, S. $270 \mathrm{f}$.

13 Erfasst werden (1.) die Ausübung des Rechts auf Suche, Erhalt, Übergabe, Herstellung und Verbreitung von Information, (2.) die Anwendung von Informationstechnologien und (3.) die Gewährleistung des Informationsschutzes.

14 Eine Übersicht über die Änderungen findet sich bei E.А. Тигранян, Контент интернетизданий: формирование и правовое регулирование (на примере изданий „Российская Газета“ и „Новая Газета") (Tigranjan, Inhalt von Internet-Ausgaben: Formierung und rechtliche Regulierung (am Beispiel der Ausgaben „Rossijskaja Gazeta“ und „Novaja Gazeta“), Moskau 2018, S. 90 ff. 
den Sperrverfahren in Art. 15.1. und Art. 15.3. InfoG wurden durch die FG Nr. 139FZ ${ }^{15}$ bzw. Nr. 398-FZ ${ }^{16}$ eingeführt.

Vorschriften zum Umgang mit verbotenen Online-Informationen finden sich auch in Spezialgesetzen auf föderaler Ebene, so z. B. in Art. 13 ExtrG, ${ }^{17}$ wo die Führung einer föderalen Liste von extremistischen Materialien vorgesehen ist ${ }^{18}$ oder im KindSG ${ }^{19}$ betreffend die Kennzeichnung von Websites, die Informationen enthalten, die dem Kindeswohl schaden (Art. 14 Abs. 2 KindSG). ${ }^{20}$ Art. 4 MedienG ${ }^{21}$ verbietet den Missbrauch von Massenmedien zur Verbreitung gesetzeswidriger Informationen, worunter auch als Massenmedien registrierte Websites fallen. ${ }^{22}$ Das MedienG geht

15 Ф3 от 28 июля 2012 г. N 139-Ф3 „О внесении изменений в Ф3 О защите детей от информации, причиняющей вред их здоровью и развитию〉 и отдельные законодательные акты РФ“ (FG vom 28. Juli 2012 Nr. 139-FZ, „über die Änderung des föderalen Gesetzes ‘über den Schutz von Kindern vor Information, welche ihre Gesundheit und Entwicklung schädigt> und einzelner Gesetzgebungsakte der RF“), C3 РФ 30.7.2012 N 31 (SZRF 30.7.2012, Nr. 31, Pos. 4328).

16 Ф3 от 28 декабря 2013 г. N 398-Ф3 „О внесении изменений в Ф3 Об информации, информационных технологиях и о защите информации " (FG vom 28. Dezember 2013 Nr. 398-FZ „über die Änderung des InfoG“, С3 РФ 30.12.2013 N 52 (часть I), ст. 6963 (SZRF 30.12.2013, Nr. 52 (T. 1), Pos. 6963).

17 Ф3 от 25 июля 2002 г. N 114-Ф3 „О противодействии экстремистской деятельности“(FG vom 25. Juli 2002 Nr. 114-FZ, ,über die Verhinderung von extremistischen Aktivitäten“), C3 РФ 29.7.2002 N 30, ст. 3031 (SZRF 29.7.2002, Nr. 30, Pos. 3031).

18 Die Liste ist auf der Internetseite des Justizministeriums der RF verfügbar: http://minjust.ru/ ru/extremist-materials, 15.1.2019. Die Materialien werden im Gegensatz zu den Sperrverfahren im InfoG allerdings nur auf Grundlage der Entscheidung eines föderalen Gerichts in die Liste aufgenommen (vgl. Art. 13 ExtrG). C.E. Чаннов, Ограничение доступа к отдельным видам информации в сети интернет (С̆annov, Sperre des Zugangs zu einzelnen Arten von Information im Internet), Власть (Gewalt) 6|2013, S. 84; Л.К. Терещенко, Модернизация информационных отношений и информационного законодательства (Tereščenko, Modernisierung der Informationsbeziehungen und der Informationsgesetzgebung), Moskau 2013, S. 203.

19 Ф3 от 29 декабря 2010 г. N 436-Ф3 „О защите детей от информации, причиняющей вред их здоровью и развитию“ (FG vom 29. Dezember 2010 Nr. 436-FZ, ,über den Schutz von Kindern vor Information, welche ihre Gesundheit und Entwicklung schädigt"), C3 РФ 3.1.2011 N 1, ст. 48 (SZRF 3.1.2011, Nr. 1, Pos. 48).

20 Терещенко (Tereščenko), Fn. 18, S. 200.

21 Закон РФ от 27 декабря 1991 г. N 2124-1 „О средствах массовой информации“ (Gesetz vom 27. Dezember 1991 Nr. 2124-1, ,über die Massenmedien“), ,Ведомости СНД и ВС РФ“ 13.2.1992 N 7, ст. 300 (,,Vedomosti SNG i VS RF“), 13.2.1992, Nr. 7, Pos. 300.

22 Es besteht keine Verpflichtung zur Registrierung von Websites als Online-Massenmedien. Eine nicht registrierte Website gilt unabhängig von ihrer tatsächlichen Beschaffenheit nicht als Massenmedium (vgl. Art. 8 Abs. 2 MedienG). Dazu Punkt 6 in Постановление Пленума Верховного Суда РФ от 15 июня 2010 г. N 16 „О практике применения судами Закона РФ 〈О средствах массовой информации “ (Urteil des Plenums des Obersten Gerichtshofs der RF (im Folgenden: OG RF) vom 15. Juni 2010 Nr. 16 , über die Praxis der Anwendung des MedienG durch die Gerichte“), Бюллетень Верховного Суда РФ N 8 от 31 августа 2010 г. (Bulletin des OG RF Nr. 8, 31.8.2010); В.И. Кайнов, Информационное право России (Kajnov, Informationsrecht Russlands), Rostow am Don 2014, S. 103 ff. Die betreffenden Journalisten können sich entsprechend nicht auf die Journalistenrechte in Art. 47 MedienG berufen. C. von Gall, Kommentar zu Art. 29 VfRF, in: B. Wieser (Hrsg.), Handbuch der russischen Verfassung, Wien 2014, N 63. 
dem InfoG im Bereich der Online-Massenmedien als lex specialis vor (vgl. Art. 4 Abs. 2 InfoG), ${ }^{23}$ jedoch decken sich die Tatbestände des Missbrauchs von Massenmedien in Art. 4 MedienG weitgehend mit denjenigen im InfoG. ${ }^{24}$

Die im InfoG vorgesehenen Sperrmechanismen werden unmittelbar gestützt auf Delegationsnormen im InfoG durch die Regierung der RF in Akten auf Verordnungsstufe konkretisiert. So wurde gestützt auf Art.15.1. Abs. 3 InfoG die Verordnung (VO) vom 26. Oktober 2012 Nr. $1101^{25}$ erlassen, welche die Bildung und Führung des Einheitlichen Registers der verbotenen Internetressourcen regelt.

\section{Regionale Ebene}

Von Art. 71 Bst. „И“ VfRF wird nach dem Wortlaut nicht sämtliche, sondern lediglich föderale Information erfasst. ${ }^{26}$ Angesichts der Abgrenzungsschwierigkeiten wird faktisch von einer ausschließlichen Kompetenz der RF ausgegangen. ${ }^{27}$ Die Regulierungskompetenzen der regionalen Gesetzgeber werden im Bereich der Sperre von Online-Inhalten zusätzlich durch den sich aus Art. 55 Abs. 3 VfRF ergebenden und in Art. 3 Abs. 2 InfoG konkretisierten Grundsatz eingeschränkt, wonach Einschränkungen des Zugangs zu Information nur durch föderale Gesetze erfolgen dürfen. ${ }^{28}$ Den Föderationssubjekten ist es auf jeden Fall erlaubt, die bundesrechtlichen Vorschriften zu konkretisieren, was v. a. im Bereich der lokalen Informationssysteme geschehen ist.

23 Auf nicht als Massenmedien registrierte Websites kann das MedienG dagegen nicht zur Anwendung kommen. Vgl. Определение ВС РФ от 16 июля 2014 г. (Beschluss des OG RF vom 16.7.2014), N 3-АПГ14-1, S. 4.

24 А.И. Савельев, Комментарий к Федеральному закону от 27 июля 2006 г. N 149-Ф3 „Об информации, информационных технологиях и защите информации“ (постатейный), (Savel'ev, Artikelweiser Kommentar zum FG vom 27. Juli 2006 Nr. 149-FZ ..über die Information, die Informationstechnologien und den Schutz von Information“, Moskau 2015, Art. 1 InfoG (zitiert nach der Datenbank „Consultant Plus"). Zur Verantwortlichkeit nach dem MedienG $V$. Monachov, Meinungsfreiheit und neue Informationstechnologien, in: A. Nußberger/C. Schmidt (Hrsg.), Medienrecht und Meinungsfreiheit in Russland, Berlin 2005, S. $129 \mathrm{ff}$.

25 Постановление Правительства РФ от 26 октября 2012 г. N 1101 „О единой автоматизированной информационной системе «Единый реестр доменных имен, указателей страниц сайтов в информационно-телекоммуникационной сети Интернет и сетевых адресов, позволяющих идентифицировать сайты в информационнотелекоммуникационной сети Интернет, содержащие информацию, распространение которой в РФ запрещено " (VO der Regierung der RF vom 26. Oktober 2012 Nr. 1101 „über das Einheitliche Register der Domain-Namen, Adressierungselemente von Internetseiten und Netzwerkadressen, welche es erlauben, Websites im Internet zu identifizieren, die Informationen enthalten, deren Verbreitung im Internet verboten ist", C3 РФ 29.10.2012 N 44, ст. 6044 (SZRF 29.10.2012, Nr. 44, Pos. 6044) (zit. VO EReg).

26 И.Л. Бачило/М.А. Лапина, Глава 3, in: Dies. (ред.), Актуальные проблемы информационного права (Bačilo/Lapina, Kapitel 3, in: Dies. (Red.), Aktuelle Probleme des Informationsrechts), Moskau 2016, S. 89.

27 Савельев (Savel'ev), Fn. 24, Art. 3 InfoG (zitiert nach der Datenbank „Consultant Plus“).

28 Савельев (Savel'ev), Fn. 24, Art. 3 InfoG (zitiert nach der Datenbank "Consultant Plus“). 
Mit dem Inkrafttreten des föderalen InfoG im Jahr 2006 wurden viele regionale Informationsgesetze aufgehoben, so z. B. in der Republik Kalmückien ${ }^{29}$ oder den Gebieten Uljanovsk ${ }^{30}$ und Moskau. ${ }^{31}$ In anderen Föderationssubjekten blieben die regionalen Informationsgesetze bestehen, so z. B. im Gebiet Orlov ${ }^{32}$ und der Stadt Moskau. ${ }^{33}$ Vereinzelt wurden neue Informationsgesetze erlassen, wie z. B in der Republik Dagestan. ${ }^{34}$ Auf kommunaler Ebene existieren Erlasse der jeweiligen Gemeinde-Administrationen, die Detailfragen im Zusammenhang mit den lokalen Informationssystemen regeln, so z. B. in der ländlichen Siedlung Borovskoe ${ }^{35}$ (Gebiet Novgorod).

\section{Sperrverfahren}

Das InfoG unterscheidet zwischen der Sperre von Online-Information, deren Verbreitung in der RF verboten ist (информация, распространение которой в РФ запрещено) in Art. 15.1. InfoG und Information, die gesetzeswidrig verbreitet wird

29 Закон Республики Калмыкия от 13 октября 2004 г. N 39-III-3 „Об информатизации и защите государственных информационных ресурсов Республики Калмыкия“" Gesetz der Republik Kalmückien vom 13. Oktober 2004 Nr. 39-III-Z ,über die Informatisierung und den Schutz der staatlichen Informationsressourcen der Republik Kalmückien“), „Хальмг Унн“" N 221-222, 22.10.2004 (Chal'mg Unn, Nr. 221-222, 22.10.2004).

30 Закон Ульяновской области от 29 сентября 2005 г. N 087-3О „Об информационных ресурсах и информатизации Ульяновской области“" (Gesetz des Gebiets Uljanovsk vom 29. September 2005 Nr. 087-ZO ,über die Informationsressourcen und die Informatisierung des Gebiets Uljanovsk), „Ульяновская правда“ N 96 (22.410), 11.10.2005 („Ul’janovskaja pravda" Nr. 96 (22.410), 11.10.2005)

31 Закон Московской области от 25 февраля 1998 г. N 9/98-ОЗ „Об информации и информатизации в Московской области“ (Gesetz des Gebiets Moskau vom 25.2.1998 Nr. 9/98-OZ ,,über die Information und die Informatisierung im Gebiet Moskau), Вестник Московской областной Думы N 5, май 1998 г. (Vestnik Moskovskoj oblastnoj Dumy, Nr. 5, Мai 1998).

32 Закон Орловской области от 13 мая 2008 г. N 774-О3 „Об информатизации и информационных ресурсах Орловской области“ (Gesetz des Gebiets Orlov vom 13.5.2008 Nr. 774-OZ ,über die Informatisierung und die Informationsressourcen im Gebiet Orlov"), Орловская правда N 76, 15.5.2008 (Orlovskaja pravda Nr. 76, 15.5.2008).

33 Закон города Москвы от 24 октября 2001 г. N 52 „Об информационных ресурсах и информатизации города Москвы“ (Gesetz der Stadt Moskau ,über die Informationsressourcen und die Informatisierung der Stadt Moskau), Ведомости Московской городской думы N 1, 2002 (Vedomosti Moskovskoj gorodskoj dumy, Nr. 1, 2002).

34 Закон Республики Дагестан от 17 октября 2014 г. N 77 „Об информатизации и государственных информационных системах Республики Дагестан“" (Gesetz der Republik Dagestan vom 17. Oktober 2014 Nr. 77 , über die Informatisierung und die staatlichen Informationssysteme der Republik Dagestan“), „Дагестанская правда“ N 409-410, 21.10.2014 („Dagestanskaja pravda“ Nr. 409-410, 21.10.2014).

35 Постановление Администрации Боровского сельского поселения от 5 мая 2014 г. N 49 „Об утверждении Положения о порядке создания, функционирования и использования муниципальных информационных систем Администрации Боровского сельского поселения" (VO der Administration der ländlichen Siedlung Borovskoe vom 5. Mai 2014 Nr. 49 , ,über die Bestätigung der Satzung über die Ordnung der Bildung, das Funktionieren und die Nutzung der kommunalen Informationssysteme der Administration von Borovskoe), http://admborovskoe.ru/documents/315.html, 15.1.2019. 
(информация, распространяемая с нарушением закона) in Art. 15.3. InfoG. Im ersten Fall ist der Inhalt der Information an sich verboten (z. B. Kinderpornographie), im zweiten Fall ist die Art und Weise der Verbreitung verwerflich (z. B. öffentlicher Aufruf zu Massenunruhen). ${ }^{36}$ Die beiden Sperrverfahren unterscheiden sich nach dem Inhalt der zu sperrenden Informationen, den beteiligten Akteuren und vom zeitlichen Ablauf her. Da das Verfahren in Art. 15.3. InfoG zeitlich abgekürzt ist und demjenigen in Art. 15.1. InfoG vorgeht (vgl. Art. 15.1. Abs. 13 InfoG), kann man es als „Eilsperre“ und dasjenige in Art. 15.1. InfoG als „ordentliches Verfahren“ bezeichnen.

Technisch stehen verschiedene Sperrmöglichkeiten zur Verfügung, die in Bezug auf die zu sperrende Information unterschiedlich präzis sind, und zwar die Sperre (1.) anhand der IP-Adresse oder (2.) des Domain-Namens von Websites, (3.) der URL einzelner Internetseiten und (4.) anhand von Datenpaketen. „Roskomnadzor“ hat sich grundsätzlich für die Kombinationslösung „IP+URL“ ausgesprochen. ${ }^{37}$

\section{Ordentliches Verfahren (Art. 15.1. InfoG)}

a) Das einheitliche Register der verbotenen Internetressourcen

Herzstück des ordentlichen Verfahrens ist das „Einheitliche Register der Domain-Namen, Adressierungselemente von Internetseiten und Netzwerkadressen, welche es erlauben, Websites im Internet zu identifizieren, die Informationen enthalten, deren Verbreitung im Internet verboten ist" (im Folgenden: EReg). Das EReg dient der Identifizierung von Websites, die verbotene Informationen enthalten (,,blacklist“) ${ }^{38}$ Mit der Aufnahme ins EReg erfolgt keine unmittelbare Sperre der Website durch die Staatsorgane, dem Eigentümer derselben wird vielmehr zuerst Gelegenheit eingeräumt, die beanstandete Information freiwillig zu löschen.

Ins EReg werden nach Art. 15.1. Abs. 2 InfoG zum einen Domain-Namen (доменное имя) und IP-Adressen (сетевой адрес) zur Identifizierung ganzer Websites (веб-сайт) und zum anderen Adressierungselemente einzelner Webseiten (указатели веб-страницы) aufgenommen. ${ }^{39}$ Das Register ist unter http://eais.rkn.gov. ru/ abrufbar, allerdings können gewöhnliche Internetnutzer die Liste der Internetres-

36 In Art. 5 Abs. 3 Ziff. 1-4 InfoG werden nach der Zugänglichkeit und der Verbreitung verschiedene Arten von Information unterschieden. Dazu Кузнецов (Киznесоv), Fn. 11, S. $224 \mathrm{f}$.

37 Vgl. zu den Sperrtechniken den Bericht von „Rozkomnadzor“ vom April 2013 „Анализ существующих методов управления доступом к интернет-ресурсам и рекомендации по их применению“ (Analyse der existierenden Methoden der Verwaltung des Zugangs zu Internetressourcen und der Empfehlungen zum Umgang mit denselben"), https://rkn.gov.ru/ docs/Analysys_and_recommendations_comments_fin.pdf, 15.1.2019 (zit. Bericht „Rozkomnadzor" Sperrtechniken). Zu den Problemen in der Praxis hinten III.4.b) und IV.2.

38 Von Gall, Fn. 22, N 34; Савельев (Savel'ev), Fn. 24, Art. 15.1 InfoG (zitiert nach der Datenbank „Consultant Plus").

39 Websites sind Internetpräsenzen, die i. d. R. eine Vielzahl von einzelnen Webseiten umfassen. Websites können durch einen Domain-Namen und eine IP-Adresse (Internet Protocol address) im Internet identifiziert werden, einzelne Webseiten durch eine URL (Universal Resource Locator). Der Begriff Internetressource (интернет-ресурс) wird als Sammelbegriff verwendet. Vgl. hierzu die Begriffsbestimmungen in Art. 2 Ziff. 13-16 InfoG und K.K. Михельсон, Информационное право (Michel'son, Informationsrecht), Moskau 2016, S. 82. 
sourcen, die verbotene Informationen enthalten, nicht frei einsehen. Nach Ziff. 5 OrdZEReg $^{40}$ besteht lediglich die Möglichkeit, mithilfe einer Suchfunktion das Vorhandensein von Internetressourcen im Register zu überprüfen. ${ }^{41}$

Die Bildung und Führung des EReg obliegt nach Art. 15.1. Abs. 3 InfoG „Roskomnadzor". ${ }^{42}$ Das EReg wird in elektronischer Form im 24-Stunden-Betrieb geführt (Ziff. 4 Vorschr. Führung VO EReg) ${ }^{43}$ Der Inhalt besteht nach Ziff. 16 VO EReg aus einzelnen Registereinträgen (реестровые записи), die detaillierte Informationen zur Sperre der beanstandeten Internetressourcen enthalten (vgl. Ziff. 9 und 17 Vorschr. Führung VO EReg).

\section{b) Aufnahmegründe}

Domain-Namen, Adressierungselemente und Netzwerkadressen werden ins EReg aufgenommen, wenn festgestellt wird, dass sie verbotene Informationen enthalten. Anlass zur Aufnahme ins EReg bildet nach Art. 15.1. Abs. 5 InfoG entweder eine Entscheidung des zuständigen föderalen Exekutivorgans (Ziff. 1) oder eine (rechtskräftige $)^{44}$ Gerichtsentscheidung (Ziff. 2) betreffend die Qualifizierung einer Information als verboten. ${ }^{45}$

40 Приказ Роскомнадзора от 9 июня 2017 г. N 100 „Об утверждении Порядка доступа к информации, содержащейся в единой автоматизированной информационной системе «Единый реестр доменных имен, указателей страниц сайтов в информационнотелекоммуникационной сети Интернет и сетевых адресов, позволяющих идентифицировать сайты в информационно-телекоммуникационной сети Интернет, содержащие информацию, распространение которой в РФ запрещено " (Erlass von Roskomnadzor vom 9. Juni 2017 Nr. 100 , über die Bestätigung der Ordnung des Zugangs zu Information, die im EReg enthalten ist"), зарегистрировано в Минюсте России 18.8.2017 N 47856 (registriert im Justizministerium der RF am 18.8.2017, Nr. 47856) (zit. OrdZEReg).

41 Für die föderalen Exekutivorgane, Strafverfolgungsbehörden, Netzwerkbetreiber und registrierten Eigentümer von Websites sind hingegen nach Ziff. 2, 3, 4 und 6 OrdZEReg eigene Zugangsregimes vorgesehen.

42 Es besteht nach Art. 15.1 Abs. 4 InfoG die Möglichkeit, als faktischen Betreiber (оператор) eine Organisation beizuziehen, die in der RF registriert ist, was bisher aber nicht geschehen ist.

43 Im Anhang zur VO EReg befinden sich die „Правила создания, формирования и ведения единой автоматизированной информационной системы Единый реестр доменных имен, указателей страниц сайтов в информационно-телекоммуникационной сети Интернет и сетевых адресов [...] (,Vorschriften über die Bildung, Ausgestaltung und Führung des EReg") (zit. Vorschr. Führung VO EReg).

44 Das Wort „,rechtskräftig“ wurde durch Art. 14 Ф3 от 28 ноября 2018 г. N 451-Ф3 „О внесении изменений в отдельные законодательные акты РФ“ (FG vom 28. November 2018 Nr. 451-FZ, über die Änderung einzelner Gesetzesakte der RF“), C3 РФ 3.12.2018, N 49 (часть I), ст. 7523, (SZRF 3.12.2018, Nr. 49 (Teil I), Pos. 7523) (zit. Änderungsgesetz Nr. 451-FZ) gelöscht, wobei die Änderung erst mit der Aufnahme der Tätigkeit der Kassations- und Appellationsinstanzen der allgemeinen Gerichtsbarkeit in Kraft treten wird.

45 Михельсон (Michel'son), Fn. 39, S. 82 f. Daneben wird seit dem 23. April 2018 in Art. 15.1. Abs. 5 Ziff. 3 InfoG auch die Verfügung eines Gerichtsvollziehers betreffend ehr- oder rufschädigende Informationen genannt. Vgl. Ф3 от 23 апреля 2018 г. N 102-Ф3 „О 
Im Fall der Entscheidung eines föderalen Exekutivorgans nennt Art. 15.1. Abs. 5

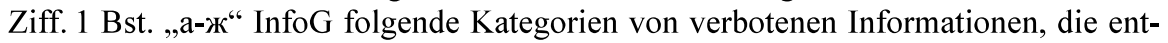
weder Straftatbestände erfüllen ${ }^{46}$ oder spezialgesetzlich verboten sind:

Kinderpornographische Materialen i. S. v. Art. 242.1. StGB $\mathrm{RF}^{47}$ und Anzeigen über die Anwerbung von Minderjährigen als Darsteller zur Teilnahme an pornografischen Vorstellungen für Zuschauer nach Art. 242.2. StGB RF (Bst. ,a“); Information über die Verfahren und Methoden der Entwicklung, Herstellung und Nutzung von Drogen, psychoaktiven Substanzen und ihrer Vorläufer, neuer potentiell gefährlicher psychoaktiver Stoffe sowie über die Orte ihrer Beschaffung und die Verfahren zur Kultivierung von Pflanzen, die Drogenstoffe enthalten i. S. v. Art. $228 \mathrm{ff}$. StGB RF (Bst. „б"); Information über die Methoden von und Aufrufe zu Selbstmord nach Art. 110-110.2. StGB (Bst. „B“); Information betreffend minderjährige Opfer von unrechtmäßigen Handlungen (Unterlassungen), deren Verbreitung nach Art. 5 Abs. 2 Ziff. 8 KindSG und Art. 4 Abs. 6 MedienG verboten ist (Bst. „Г"); Information, welche die Vorschriften des Glücksspiel- ${ }^{48}$ und Lotteriegesetzes ${ }^{49}$ betreffend das Verbot der Organisation und Durchführung von Online-Glücksspielen (Art. 5 Abs. 3 GsG) und Lotterien (Art. 6.1. Abs. 4 LG) im Internet verletzt (Bst. „„“); Information, die Angebote über den gesetzeswidrigen Fern-Einzelhandel mit alkoholischen Lebensmittel- oder Non-Food-Produkten oder Ethylalkohol, die nach Art. 26 Abs. 2.1. $\mathrm{AlkG}^{50}$ verboten oder eingeschränkt werden, enthält (Bst. ,e“") sowie neu Information, die auf die Zuführung oder andere Form der Beiziehung von Minderjährigen zur

внесении изменений в Ф3 ८Об исполнительном производстве〉и статью 15.1. Ф3 ८Об информации, информационных технологиях и о защите информации “ (FG vom 23. April 2018 Nr. 102-FZ, über die Änderung des FZ (über das Vollzugsverfahren〉 und Art. 15.1. InfoG“), С3 РФ 30.4.2018 N 18, ст. 2572 (SZRF 30.4.2018, Nr. 18, Pos. 2572).

46 Die Sperre von Online-Inhalten ist nur eine administrative (Zwangs-)Maßnahme. Dazu kommt - je nachdem - die strafrechtliche oder verwaltungsstrafrechtliche Verantwortlichkeit. Das OG RF verneinte die verwaltungsrechtliche Verantwortlichkeit eines HostingProviders betreffend die Aufschaltung extremistischer Materialien. Vgl. Постановление ВС РФ от 15 декабря 2014 г. (Urteil des OG RF vom 16.7.2014), N 31-AД14-11.

47 „Уголовный кодекс РФ“ от 13 июня 1996 г. N 63-Ф3 (,,Strafgesetzbuch der RF“ vom 13. Juni 1996 Nr. 63-FZ), C3 РФ 17.6.1996 N 25, ст. 2954 (SZRF 17.6.1996, Nr. 25, Pos. 2954)

48 Ф3 от 29 декабря 2006 г. N 244-Ф3 „О государственном регулировании деятельности по организации и проведению азартных игр и о внесении изменений в некоторые законодательные акты РФ“ (FG vom 29. Dezember 2006 Nr. 244-FZ, ,über die staatliche Regulierung der Aktivität zur Organisation und Durchführung von Glücksspielen und über die Änderung einiger Gesetzesakte der RF“"), C3 РФ 1.1.2007 N 1 (1 ч.), ст. 7 (SZRF 1.1.2007, Nr. 1 (1. Teil), Pos. 7).

49 ФЗ от 11 ноября 2003 г. N 138-Ф3 „О лотереях“ (FG vom 11. November 2003 Nr. 138-FZ „über die Lotterien“), C3 РФ 17.11.2003 N 46 (ч. 1), ст. 4434 (SZRF 17.11.2003, Nr. 46 (Teil 1), Pos. 4434).

50 ФЗ от 22 ноября 1995 г. N 171-Ф3,,О государственном регулировании производства и оборота этилового спирта, алкогольной и спиртосодержащей продукции и об ограничении потребления (распития) алкогольной продукции“ (FG vom 22. November 1995 Nr. 171-FZ ,über die staatliche Regulierung der Produktion und des Umsatzes von Ethylalkohol, alkoholischer und alkoholhaltiger Erzeugnisse und die Einschränkung des Konsums (Alkoholkonsum) von Alkoholerzeugnissen), C3 РФ 27.11.1995 N 48, ст. 4553 (SZRF 27.11.1995, Nr. 48, Pos. 4553). 
Verübung von widerrechtlichen Handlungen abzielt, welche eine Gefahr für das Leben oder die Gesundheit solcher Minderjährigen oder anderer Personen darstellen (Bst. „ж“). ${ }^{51}$ Die Formulierung „Information über“ („информация о“) ist unglücklich gewählt, da darunter auch objektive Beschreibungen der betreffenden Themenkomplexe in Online-Enzyklopädien fallen. ${ }^{52}$

In Abhängigkeit von den soeben genannten Sachgegenständen sind nach Ziff. 1-4 Vorschr. Entscheidung VO EReg ${ }^{53}$ folgende föderalen Exekutivorgane zur Entscheidung über die Qualifizierung einer Online-Information als verboten berechtigt: (1.) das Innenministerium der RF im Fall von Informationen im Zusammenhang mit Drogen und anderen psychoaktiven Stoffen, (2.) der Föderale Dienst für die Aufsicht im Verbraucherschutz und Schutz des menschlichen Wohlergehens(„Rospotrebnadzor“) bei Information über Suizid, (3.) „Roskomnadzor" bei Kinderpornographie allgemein sowie Information über Drogen und Suizid, falls sie von einem registrierten OnlineMassenmedium i. S. v. Art. 8 MedienG angeboten wird, ${ }^{54}$ (4.) der Föderale Steuerdienst im Fall von Online-Glücksspielen und Lotterien sowie (5.) der Föderale Dienst zur Regulierung des Alkoholmarkts bei Informationen über den gesetzeswidrigen Einzelhandel mit alkoholischen Erzeugnissen. ${ }^{55}$ Die Zuständigkeit bei Informationen im Zusammenhang mit minderjährigen Opfern i. S. v. Art. 15.1. Abs. 5 Ziff. 1 Bst. „Г“ InfoG wird in der VO EReg nicht bestimmt. ${ }^{56}$

Grundlage zur Aufnahme von Internetressourcen ins EReg bilden auch rechtskräftige Gerichtsentscheidungen, in denen Informationen als verboten qualifiziert werden (Art. 15.1. Abs. 5 Ziff. 2 InfoG i. V. m. Ziff. 5 Bst. „б“ Vorschr. Führung VO EReg). ${ }^{57}$ Die thematische Beschränkung auf die Kategorien in Art. 15.1. Abs. 5 Ziff. 1 InfoG

51 Der Aufnahmegrund lässt sich auf die Gesetzesinitiative von I. Jarovaja zurückführen. Dazu vorne I.

52 Dazu die Sperrfälle in der Praxis hinten III.4.b).

53 Im Anhang zur VO EReg befinden sich die „Правила принятия уполномоченными Правительством РФ федеральными органами исполнительной власти решений в отношении отдельных видов информации и материалов, распространяемых посредством информационно-телекоммуникационной сети 〈Интернет〉, распространение которых в РФ запрещено“ (.,Vorschriften zur Entscheidung durch die von der Regierung der RF ermächtigten föderalen Exekutivorgane betreffend einzelne Arten von Informationen und Materialien, die über das Internet verbreitet werden und deren Verbreitung in der RF verboten ist").

54 „Roskomnadzor“ führt unter http://rkn.gov.ru/mass-communications/reestr/media/, 15.1.2019 ein Register der registrierten Massenmedien. Zur Registrierung von Online-Medien vorne II. 1.

55 T.A. Полякова, Глава 11 (Poljakova, Kapitel 11), in: Бачило/Лапина (Bačilo/Lapina) (Hrsg.), Fn. 26, S. 405 f. Zu den Kompetenzen von „Roskomnadzor“ Кайнов (Kajnov), Fn. 22, S. $68 \mathrm{f}$.

56 Савельев (Savel'ev), Fn. 24, Art. 15.1. InfoG (zitiert nach der Datenbank „Consultant Plus“) schlägt die Polizei vor.

57 Mit der Gerichtsentscheidung erfolgt nicht nur eine rechtliche Qualifizierung der betreffenden Information, sondern es wird gleichzeitig die Verpflichtung des Website-Eigentümers zur Löschung derselben begründet. Vgl. Обзор судебной практики ВС РФ N 2, 2018 (Übersicht über die Rechtsprechungspraxis des OG RF Nr. 2, 2018), „Бюллетень трудового и социального законодательства РФ“ N 72018 (.,Bulletin des Arbeits- und Sozialrechts der RF“Nr. 7, 2018), Punkt 42, S. 105 (zit. Übersicht Rechtsprechungspraxis OG RF Nr. 2, 2018). 
gilt hier nicht, weshalb v. a. spezialgesetzlich verbotene Informationen eine Rolle spielen. Von praktischer Bedeutung sind die von einem Gericht für „extremistisch“ befundenen Materialien nach Art. 12 ExtrG. ${ }^{58}$

\section{c) Ablauf}

Durch das bereits erwähnte Änderungsgesetz Nr. 472-FZ vom 18. Dezember 2018 wurde das ordentliche Sperrverfahren unter dem Deckmantel des Kindesschutzes ${ }^{59}$ stark gestrafft und in zeitlicher Hinsicht der Eilsperre angenähert. Im Folgenden werden die bisherige und die Rechtslage seit dem 29. Dezember 2018 parallel dargestellt.

Das ordentliche Verfahren in Art. 15.1. InfoG wird nur auf Grundlage einer Eingabe (обращение) von Staats- oder Gemeindeorganen, juristischen Personen, Einzelunternehmern, gesellschaftlichen Vereinigungen, anderen nichtkommerziellen Organisationen oder Bürgern über das Vorhandensein von verbotenen Informationen auf einer Website anberaumt (vgl. Ziff. 6 Vorschr. Führung VO EReg). ${ }^{60}$ Das Formular für die Eingabe steht unter https://eais.rkn.gov.ru/ zur Verfügung.

Die Eingabe wird nach Empfang in elektronischer Form an das sachlich zuständige föderale Exekutivorgan weitergeleitet, ${ }^{61}$ das innerhalb von 24 Stunden (bei Notwendigkeit der Durchführung einer Expertise innerhalb von sieben Tagen) nach Eingang der Eingabe über das Vorliegen von verbotenen Informationen entscheidet und „Roskomnadzor" über das Ergebnis informiert (Ziff. 7 und 8 Vorschr. Führung VO EReg). ${ }^{62}$ „Roskomnadzor“ nimmt dann gestützt auf die Entscheidung des föderalen Exekutivorgans oder die rechtskräftige Gerichtsentscheidung über die Qualifizierung einer Information als verboten innerhalb von 24 Stunden den Eintrag im EReg vor (Ziff. 9 Vorschr. Führung VO EReg).

Danach ermittelt der zuständige Mitarbeiter von „Roskomnadzor“ den HostingProvider und informiert diesen sowie - falls bekannt - den Eigentümer der Website (владелец сайта) ${ }^{63}$ in elektronischer Form auf Russisch und Englisch über die Auf-

58 So auch von Gall, Fn. 22, N 35. Vgl. z. В. Определение КС РФ от 22 декабря 2015 г. (Beschluss des Verfassungsgerichts der RF (VfG RF) vom 22.12.2015), N 3024-O sowie Постановление ВС РФ от 15 декабря 2014 г. (Urteil des OG RF vom 15. Dezember 2014), N 31-АД14-11 m. w. Н. auf die Rechtsprechung der regionalen Gerichte.

59 Im Gesetzesentwurf von I. Jarovaja wurde verschleiert, dass die Möglichkeit der sofortigen Blockierung des Zugangs nicht nur für Online-Inhalte gilt, in denen Kinder zu Selbstmord oder der Begehung von Verbrechen angehalten werden, sondern für sämtliche Aufnahmegründe in Art. 15.1. Ziff. 5 InfoG. Vgl. die erklärende Notiz zum Gesetzesentwurf Nr. 469143-7, http://sozd.parliament.gov.ru/bill/469143-7, 15.1.2019.

60 „Roskomnadzor" betreibt (anders als die Generalstaatsanwaltschaft der RF bei der Eilsperre) keine aktive Überwachung des Internets. Савельев (Savel'ev), Fn. 24, Art. 15.1. InfoG (zitiert nach der Datenbank „Consultant Plus“).

61 Zur sachlichen Zuständigkeit vorne III.1.b).

62 Vgl. zum Verfahrensablauf Übersicht Rechtsprechungspraxis OG RF Nr. 2, 2018, Fn. 57 , Punkt 42, S. 104 f. und Кайнов (Kajnov), Fn. 22, S. 91 ff.

63 Der Website-Eigentümer wird in Art. 2 Ziff. 17 InfoG folgendermaßen definiert: „Eine Person, welche selbständig und nach eigenem Ermessen die Nutzung einer Website und die Aufschaltung von Information bestimmt". Anbieter von Suchmaschinen erfüllen diese Anforderungen nicht, weshalb Websites von Suchmaschinen aufgrund des Inhalts der 
nahme des Domains-Namens der Website und/oder der URL der Webseite ins EReg (Ziff. 11 Vorschr. Führung VO EReg). Der Hosting-Provider (провайдер хостинга) ${ }^{64}$ ist verpflichtet, den Eigentümer der Website unmittelbar (bisher: innerhalb von 24 Stunden) über den Registereintrag und die Notwendigkeit zur sofortigen Löschung der Webseite mit der verbotenen Information (nicht aber der gesamten Website) zu informieren (Art. 15.1. Abs. 7 InfoG). Weigert sich der Eigentümer der Website oder bleibt er untätig, schränkt der Hosting-Provider den Zugang zur Website sofort (bisher: nach Ablauf von 24 Stunden) ein (Art. 15.1. Abs. 8 InfoG). Bleiben sowohl der Website-Eigentümer als auch der Hosting-Provider untätig, wird die Netzwerkadresse (IP-Adresse) der betreffenden Website ins EReg aufgenommen und der Netzwerkbetreiber (оператор связи) verpflichtet, den Zugang zur Website innerhalb von 24 Stunden einzuschränken (Art. 15.1. Abs. 9 und 10 InfoG) ${ }^{65}$ Im ordentlichen Verfahren hat der Website-Eigentümer damit die Möglichkeit, den beanstandeten Inhalt freiwillig zu löschen, bevor die staatliche Blockierung der Website erfolgt. ${ }^{66}$

Die Entfernung des Eintrags aus dem EReg erfolgt nach Art. 15.1. Abs. 11 InfoG einerseits auf Gesuch des Website-Eigentümers, Hosting-Providers oder Netzwerkbetreibers hin, falls die verbotene Information inzwischen gelöscht wurde, was von einem Mitarbeiter von „Roskomnadzor“ überprüft wird (Ziff. 12 Vorschr. Führung VO EReg). Andererseits wird der Registereintrag auch dann gelöscht, wenn eine rechtskräftige Gerichtsentscheidung über die Aufhebung der Entscheidung des zuständigen föderalen Exekutivorgans vorliegt, die Grundlage zur Aufnahme der Internetressource ins EReg bildete (Art. 15.1. Abs. 11 InfoG und Ziff. 14 Bst. „a“ Vorschr. Führung VO EReg). Der Zugang zur blockierten Ressource wird nach Löschung des Registereintrags vom Netzwerkbetreiber innerhalb von 24 Stunden wiederhergestellt (Ziff. 15 Vorschr. Führung VO EReg) ${ }^{67}$

angezeigten Treffer nicht ins EReg aufgenommen werden können. Dazu Разъяснение Роскомнадзора от 30 ноября 2012 г. „По вопросу о включении в реестр запрещенной информации ссылок на результаты поисковых запросов в поисковых системах“ (Erläuterungen von „Roskomnadzor" vom 30. November 2012 ,zur Frage betreffend die Aufnahme von Links der Resultate von Suchanfragen in Suchmaschinen“, http://www.cons ultant.ru/document/cons_doc_LAW_138409/, 15.1.2019 (zit. Erläuterungen ,Roskomnadzor").

64 Nach Art. 2 Ziff. 18 InfoG ist der Hosting-Provider eine Person, die Rechenleistung bereitstellt, um Informationen im Internet aufzuschalten. Zum Rechtsstatus des Hosting-Providers Кайнов (Kajnov), Fn. 22, S. $80 \mathrm{ff}$.

$65 \mathrm{Zu}$ den Problemen im Zusammenhang mit der Sperrtechnik anhand der Netzwerkadresse hinten III.4.b) und IV.2.

66 Савельев (Savel'ev), Fn. 24, Art. 15.1. InfoG (zitiert nach der Datenbank, „Consultant Plus“); Обзор судебной практики ВС РФ N 2, 2015 (Übersicht über die Rechtsprechungspraxis des OG RF Nr. 2, 2015), „Бюллетень Верховного Суда РФ“, N 10 октябрь 2015 (,Bulletin des OG RF“, Nr. 10, Oktober 2015), Punkt 3, S. 52.

67 In der Sperrpraxis von ,Roskomnadzor“ sind allerdings Fälle von (gerichtlich angeordneten) „,ewigen Sperren“ (вечная блокировка) bekannt, wie z. B. bei „RuTracker“. Dazu hinten IV. 7 . 
2. Eilsperre (Art. 15.3. InfoG)

a) Begriff und Abgrenzung zum ordentlichen Verfahren

Mit dem bereits erwähnten Änderungsgesetz Nr. 398-FZ (sog. „Закон Лугового“, „Gesetz von Lugovoj“) wurde in Art. 15.3. InfoG die Möglichkeit geschaffen, den Zugang zu Internetressourcen (i. d. R. Websites) auf Verlangen der Generalstaatsanwaltschaft der RF sofort einzuschränken, wenn diese Informationen auf bestimmte Art und Weise verbreiten („Eilsperre“). Die Blockierung erfolgt hier möglichst rasch, da davon ausgegangen wird, dass die Zugänglichkeit derartiger Informationen schwerwiegende Folgen für die öffentliche Sicherheit und Ordnung Russlands nach sich ziehen könnte. ${ }^{68}$ Durch das Änderungsgesetz Nr. 472-FZ wurden die Möglichkeiten zur sofortigen Blockierung von Online-Inhalten auch im ordentlichen Verfahren erweitert. ${ }^{69}$

Die Blockierung der Websites erfolgt im Verfahren der Eilsperre ausschließlich auf die Aufforderung des Generalstaatsanwalts der RF (Генеральный прокурор РФ) oder seiner Vertreter (im Folgenden: Generalstaatsanwaltschaft RF (GSA RF)) hin. Durch eine Gerichtsentscheidung kann die Eilsperre - anders als das ordentliche Verfahren - weder eingeleitet noch beendet werden. Außerdem ist das Verfahren der Eilsperre zeitlich abgekürzt, da die Blockierung der Website umgehend und nicht erst nach Untätigkeit des Website-Eigentümers erfolgt.

Bei der Eilsperre wird kein Eintrag im EReg vorgenommen, sondern die Sperraufforderung der GSA RF wird den Adressaten über das sog. „Informationssystem der Zusammenarbeit (ISZ)“ („Информационная система взаимодействия“) übermittelt, das in der VO ISZ ${ }^{70}$ konkretisiert wird. ${ }^{71}$ Das ISZ enthält nach Ziff. 2 Bst. „, $3^{\text {“ VO }}$ ISZ ein spezielles Untersystem zur Erfassung der Sperraufforderungen der GSA RF, sog. „Реестр Лугового“ („Register von Lugovoj“). Unter http://398-fz.rkn.gov.ru/ können - ähnlich wie beim EReg - Suchanfragen zur Überprüfung des Vorhandenseins bestimmter Internetressourcen im Register gestellt werden (Ziff. 3 VO ISZ).

b) Eingriffstatbestände

Sperrgegenstand im Verfahren nach Art. 15.3. InfoG ist Online-Information, die gesetzeswidrig verbreitet wird (информация, распространяемая с нарушением

68 Das Verfahren diene dem Schutz der Verfassungsstruktur und der Aufrechterhaltung der öffentlichen Ordnung Кузнечов (Киzпесоv), Fn. 11, S. 231; Савельев (Savel'ev), Fn. 24, Art. 15.3. InfoG (zitiert nach der Datenbank „Consultant Plus").

69 Dazu vorne III.1.c).

70 Приказ Роскомнадзора от 12 августа 2013 г. N 912 „О порядке функционирования Информационной системы взаимодействия“" (Erlass von „Roskomnadzor“ vom 12. August 2013 Nr. 912 ,über die Ordnung des Funktionierens des ISZ“), зарегистрировано в Минюсте России 26.11.2013 N 30454 (registriert im Justizministerium der RF am 26.11.2013, Nr. 30454) (zit. VO ISZ).

71 Nach Ziff. 1 VO ISZ dient das ISZ dem Informationsaustausch zwischen „Roskomnadzor“, den Hosting-Providern, Netzwerkbetreibern und anderen Akteuren im Zusammenhang mit der Sperre von Online-Ressourcen auf der Grundlage von Art. 15.3. InfoG (Eilsperre). 
закона). Die gesetzeswidrige Verbreitung besteht im (öffentlichen) Aufruf (призыв) ${ }^{72}$ zu bestimmten (strafbaren) Handlungen. Genannt werden: (1.) der Aufruf zu Massenunruhen (Art. 212 Abs. 3 StGB RF), ${ }^{73}$ (2.) der Aufruf zur Ausübung extremistischer Tätigkeiten ${ }^{74}$ i. S. v. Art. 280 StGB RF und (3.) der Aufruf zur Teilnahme an (öffentlichen) Massenveranstaltungen, die in Verletzung der Verfahrensvorschriften im VersG ${ }^{75}$ durchgeführt werden. ${ }^{76}$ Ein neuer Eingriffstatbestand wurde im Jahr $2017^{77}$

72 Ein Aufruf ist ,.ein in beliebiger Form (mündlich, schriftlich, unter Nutzung von Informationstechnologien, Informationssystemen) an andere Personen gerichteter Appell mit dem Ziel, in diesen den Wunsch zu wecken, bestimmte Handlungen zu verüben“. Vgl. Постановление Пленума ВС РФ от 28 июня 2011 г. N 11 „О судебной практике по уголовным делам о преступлениях экстремистской направленности“, (Urteil des Plenums des OG RF vom 28. Juni 2011 Nr. 11 ,über die Gerichtspraxis zu strafrechtlichen Fällen betreffend Verbrechen extremistischer Ausrichtung)“, „Бюллетень Верховного Суда РФ“, N 8 август 2011 (.,Bulletin des OG RF“, Nr. 8, August 2011), Punkt 4 (zit. Urteil Plenum OG RF 2011). Dazu auch Г.A. Есаков (ред.), Комментарий к Уголовному кодексу РФ (постатейный) (Esakov, Artikelsweiser Kommentar zum StGB RF), 6. Aufl., Moskau 2016, S. 346.

73 Massenunruhen zeichnen sich dadurch aus, dass sie spontan gebildet und von einem bestimmten Motiv geleitet werden sowie eine beträchtliche Zahl an Teilnehmern aufweisen. Есаков (Esakov), Fn. 72, Art. 212 StGB RF, S. 345. In diesem Sinne müssen Online-Informationen einen eigentlichen Appell enthalten, durch den ein unbestimmter Adressatenkreis zur Teilnahme an Massenunruhen angehalten wird. Fotoreportagen oder bloße Beschreibungen von Massenunruhen genügen hierzu nicht. Савельев (Savel'ev), Fn. 24, Art. 15.3. (zitiert nach der Datenbank „Consultant Plus"). Vgl. aber die Fälle in der Sperrpraxis hinten III.4.c).

74 Der Begriff der extremistischen Tätigkeit richtet sich nach Art. 1 Ziff. 1 ExtrG. Darunter fallen z. B. die gewaltsame Änderung der Verfassungsgrundlagen und die Beeinträchtigung der Integrität der RF, die öffentliche Rechtfertigung von Terrorismus, das Schüren von sozialem, Rassen-, national- und religiösem Hass. Zum Begriff der extremistischen Tätigkeit Von Gall, Fn. 22, N 33; E.В. Шленева, ст. 29, in: Ю.А. Дмитриев/Ю.И. Скуратов (ред.), Конституция Российской Федерации: доктринальный комментарий (Šleneva, Kommentar zu Art. 29 VfRF, in: Dmitriev/Skuratov (Hrsg.), Verfassung der RF: Doktrinalkommentar), 2. Aufl., Moskau 2013, S. 134 f. Zur Vollendung des Tatbestands des öffentlichen Aufrufs zu extremistischer Tätigkeit im Internet reicht es aus, dass die Information im Internet verbreitet wurde, z. B. in Blogs, Foren oder durch den Massenversand von E-Mails, unabhängig davon, ob dadurch tatsächlich jemand zur Ausübung von extremistischen Tätigkeiten angehalten wurde. Dazu Urteil Plenum OG RF 2011, Fn. 72, Punkt 4; Ecaков (Esakov), Fn. 72, Art. 280 StGB RF, S. 453.

75 Ф3 от 19 июня 2004 г. N 54-Ф3 „О собраниях, митингах, демонстрациях, шествиях и пикетированиях“ (FG vom 19. Juni 2004 Nr. 54-FZ ,über die Versammlungen, Meetings, Demonstrationen und Piketts“), С3 РФ 21.6.2004 N 25, ст. 2485 (SZRF 21.6.2004, Nr. 25, Pos. 2485).

76 Die öffentliche Veranstaltung wird in Art. 2 Ziff. 1 VersG definiert. Die Anforderungen an Organisation und Durchführung derselben finden sich in Art. 4 ff. VersG. Der Sperre durch die GSA RF unterliegen damit z. B. Informationen, die einen Aufruf zu einer öffentlichen Veranstaltung enthalten, über deren Durchführung die Staats- oder kommunalen Organe in Verletzung von Art. 7 VersG nicht oder nicht in angemessener Weise informiert wurden.

77 Ф3 от 25 ноября 2017 г. N 327-Ф3 „О внесении изменений в статьи 10.4. и 15.3. Ф3 くОб информации, информационных технологиях и о защите информации〉 и статью 6 Закона РФ 〈О средствах массовой информации〉“ (FG vom 25. November 2017 Nr. 327FZ ,über die Änderung von Art. 10.4. und 15.3. InfoG und Art. 6 MedienG“), C3 PФ 27.11.2017 N 48, ст. 7051 (SZRF 27.11.2017, Nr. 48, Pos. 7051). 
geschaffen und umfasst (4.) Informationsmaterialien ausländischer oder internationaler Nichtregierungsorganisationen, deren Tätigkeit auf dem Territorium der RF für unerwünscht befunden wurde (Art. 284.1. StGB RF). ${ }^{78}$

\section{c) Ablauf}

Nach Art. 15.3. Abs. 1 InfoG kann die gesetzeswidrig verbreitete Information entweder von der GSA RF selbst im Rahmen eines Monitorings entdeckt werden (в случае обнаружения) oder es gehen entsprechende Anzeigen (уведомления) von föderalen oder regionalen Staats- oder kommunalen Organen, Organisationen oder Bürgern ein, wobei keine Pflicht zur materiellen Überprüfung derselben besteht. ${ }^{79}$

Die GSA RF wendet sich an „Roskomnadzor“ mit der Aufforderung (требование), den Zugang zur betreffenden Website einzuschränken. Im „Register von Lugovoj" wird nach Ziff. 35 VO ISZ auf Grundlage der Aufforderung der GSA RF ein Eintrag angelegt, der zwecks Voraussehbarkeit des Verwaltungshandelns einen bestimmten Mindestinhalt aufweisen muss (vgl. Ziff. 36 VO ISZ). ${ }^{80}$ "Roskomnadzor“ sendet daraufhin den zuständigen Netzwerkbetreibern über das ISZ eine Aufforderung zur Blockierung der betreffenden Website, die umgehend (незамедлительно) vorzunehmen ist (Art. 15.3. Abs. 2 Ziff. 1 und Abs. 3 InfoG). Gleichzeitig bestimmt „Roskomnadzor" den Hosting-Provider oder eine sonstige mit dem Aufschalten der betreffenden Informationen betraute Person und informiert diesen auf Russisch und Englisch über die Sperre der Informationsressource mit der Aufforderung zur Löschung der gesetzeswidrig verbreiteten Information (Art. 15.3. Abs. 2 Ziff. 2 und 3 InfoG). Der Hosting-Provider informiert wiederum den Eigentümer der betreffenden Website innerhalb von 24 Stunden über die Sperre und hält ihn seinerseits zur Löschung der beanstandeten Information an (Art. 15.3. Abs. 4 InfoG). Die Sperre der Website kann allerdings - anders als im ordentlichen Verfahren - durch das freiwillige Löschen der Information nicht verhindert werden.

Der Eigentümer der Informationsressource kann durch eine Meldung an „Roskomnadzor" die Wiederherstellung des Zugangs zu derselben verlangen, wenn er die

78 Nach Art. 3.1 Ф3 от 28.12.2012 N 272-Ф3 „О мерах воздействия на лиц, причастных к нарушениям основополагающих прав и свобод человека, прав и свобод граждан РФ“ (FG vom 31. Dezember 2012 Nr. 272-FZ, ,über die Maßnahmen gegen Personen, die an der Störung der grundlegenden Rechte und Pflichten des Menschen und Bürgers der RF beteiligt sind"), С3 РФ 31.12.2012, N 53 (ч. 1), ст. 7597 (SZRF 31.12.2012, Nr. 53 (Teil 1), Pos. 7597) kann die Tätigkeit von ausländischen oder internationalen Nichtregierungsorganisationen, die eine Bedrohung für die Grundlagen der Verfassungsstruktur der RF, die Wehrfähigkeit des Landes oder die Staatssicherheit darstellen, auf dem Territorium der RF für unerwünscht erklärt werden.

79 Савельев (Savel'ev), Fn. 24, Art. 15.3. (zitiert nach der Datenbank „Consultant Plus“).

80 Für die Betroffenen muss erkennbar sein, welche Informationen beanstandet werden. Der Eintrag muss demnach folgende Punkte enthalten: (1.) Domain-Name der Website und/oder Adressierungselement der einzelnen Webseite, (2.) Beschreibung der beanstandeten Information, welche deren Identifizierung erlaubt, (3.) die Aufforderung der GSA RF, (4.) Zeit und Datum derselben sowie (5.) Auskünfte über den Hosting-Provider. In der Sperrpraxis wird die beanstandete Information oft nicht genau bezeichnet. Dazu hinten IV.3. 
beanstandete Information gelöscht hat (Art. 15.3. Abs. 5 InfoG). Nachdem „Roskomnadzor" die Löschung überprüft hat, ${ }^{81}$ wird der Netzwerkbetreiber zur sofortigen Wiederherstellung des Zugangs zur betreffenden Informationsressource aufgefordert (Art. 15.3. Abs. 6 und 7 InfoG).

\section{Anfechtung}

Nach Art. 15.1. Abs. 6 InfoG kann die Entscheidung über die Aufnahme von DomainNamen, Adressierungselementen von Webseiten oder Netzwerkadressen ins EReg gerichtlich angefochten werden. Anfechtungsobjekt ist die „Entscheidung über den Registereintrag (,решение о включении в реестр“), womit die Entscheidung des sachlich zuständigen Exekutivorgans über die Qualifizierung der betreffenden Information als verboten i. S. v. Art. 15.1. Abs. 5 Ziff. 1 InfoG $^{82}$ gemeint ist und nicht etwa die Vornahme des Registereintrags durch „Roskomnadzor" nach Ziff. 9 Vorschr. Führung VO EReg. ${ }^{83}$ Als Beklagter (административный ответчик) tritt aber dennoch „Roskomnadzor" auf. 84

Beschwerdeberechtigt sind nach Art. 15.1. Abs. 6 InfoG der Eigentümer der Website, der Hosting-Provider und der Netzwerkbetreiber. ${ }^{85}$ Die Beschwerdefrist beträgt drei Monate und beginnt mit dem Tag zu laufen, an dem das zuständige Exekutivorgan seine Entscheidung getroffen hat (Art. 15.1. Abs. 6 InfoG). Der Beschwerde kommt i. d. R. keine aufschiebende Wirkung zu, jedoch kann diese bei Vorliegen gewisser Voraussetzungen angeordnet werden (vgl. Art. 85 Abs. 2 i. V. m. Art. 223 VwGvK).

Streitigkeiten im Zusammenhang mit der staatlichen Blockierung von Online-Ressourcen gelten als verwaltungsrechtliche Angelegenheit (административное дело) ${ }^{86}$ i. S. v. Art. 1 Abs. 1 VwGvK, ${ }^{87}$ weshalb neben Art. 15.1. Abs. 6 InfoG die allgemei-

81 Dieses Prüfverfahren und insbesondere dessen Fristen werden nirgendwo konkretisiert, was „Roskomnadzor" einen großen Ermessensspielraum einräumt. Савельев (Savel'ev), Fn. 24, Art. 15.3. (zitiert nach der Datenbank „Consultant Plus"). Zum Problem der Verfahrenslücken im InfoG hinten IV.4.

82 Dazu vorne III.1.b).

83 Sо Савельев (Savel'ev), Fn. 24, Art. 15.1. (zitiert nach der Datenbank „Consultant Plus") und sinngemäß Übersicht Rechtsprechungspraxis OG RF Nr. 2, 2018, Fn. 57, Punkt 42, S. 105.

84 Übersicht Rechtsprechungspraxis OG RF Nr. 2, 2018, Fn. 57, Punkt 42, S. 105.

85 Das OG RF bejahte die Beschwerdebefugnis eines Domain-Administrators, der gleichzeitig auch Website-Eigentümer war. Übersicht Rechtsprechungspraxis OG RF Nr. 2, 2018, Fn. 57, Punkt 42, S. 105.

86 Erfasst werden nach Art. 1 Abs. 1 GB VwGerV verwaltungsrechtliche Angelegenheiten über den Schutz verletzter oder bestrittener Rechte, Freiheiten und gesetzlicher Interessen von Bürgern oder Organisationen sowie andere verwaltungsrechtliche Angelegenheiten, die aus verwaltungs- oder anderen öffentlichen Rechtsbeziehungen hervorgehen und mit der gerichtlichen Kontrolle über die Gesetzmäßigkeit und Begründetheit der Ausübung staatlicher oder anderer öffentlicher Kompetenzen verbunden sind. Dazu Ю.Ф. Bespalov, Комментарий к кодексу административного судопроизводства РФ (Bespalov, Kommentar zum Kodex über das Verwaltungsgerichtsverfahren der RF), Moskau 2016, S. 8 ff.

87 Кодекс административного судопроизводства РФ от 8 марта 2015 г. N 21-Ф3 (Kodex über das Verwaltungsgerichtsverfahren der RF vom 8. März 2015 Nr. 21-FZ), C3 РФ 9.3.2015 N 10, ст. 1391 (SZRF 9.3.2015, Nr. 10, Pos. 1391). 
nen Vorschriften zum verwaltungsgerichtlichen Beschwerdeverfahren zur Anwendung kommen. ${ }^{88}$ Nach Art. 1 Abs. 1 VwGvK sind damit die allgemeinen Gerichte und in letzter Instanz - in Übereinstimmung mit Art. 126 VfRF - das OG RF zuständig. Die Beschwerde wird beim zuständigen Territorialgericht am Sitz des betreffenden föderalen Exekutivorgans eingereicht (Art. 19 und $22 \mathrm{VwGvK}$ ). ${ }^{89}$ Die erstinstanzliche Gerichtsentscheidung kann vor der Appellationsinstanz im Verfahren nach Art. $295 \mathrm{ff}$. VwGvK angefochten werden. Zur Anfechtung der Sperraufforderung der GSA RF im Rahmen der Eilsperre sind in Art. 15.3. InfoG keine Spezialbestimmungen vorgesehen, jedoch gelten auch hier aus analogen Überlegungen die Bestimmungen des verwaltungsgerichtlichen Beschwerdeverfahrens. ${ }^{90}$

\section{Praxis}

a) Allgemein

„Roskomnadzor“ führt über seine Sperrpraxis gestützt auf Art. 15.1. und 15.3. InfoG keine laufende Statistik. Der Inhalt des EReg und des „Registers von Lugovoj“ kann zudem von gewöhnlichen Internetnutzern nicht offen eingesehen werden. ${ }^{91}$ Aus diesen Gründen kommt inoffiziellen Informationsquellen im Bereich der Blockierung von Internetinhalten große Bedeutung zu.

Im Rahmen des Projekts „РосКомСвобода“ („RosKomSvoboda“) wird auf der Website https://reestr.rublacklist.net/ seit 2012 ein Monitoring der Sperrpraxis der Staatsorgane im Zusammenhang mit Art. 15.1. und 15.3. InfoG betrieben, wobei sämtliche blockierten Internetressourcen aufgeführt werden. Die Website wurde im Jahr 2016 auf Grundlage einer Gerichtsentscheidung für kurze Zeit ins EReg aufgenommen, der Zugang dazu aber nicht eingeschränkt. ${ }^{92}$ Auf den Websites https://antiza pret.info/ und https://usher2.club/ wird der Inhalt des EReg ebenfalls offengelegt.

Die tatsächliche Zahl der blockierten Internetressourcen kann nur schwer bestimmt werden. Im Jahr 2017 gab „Roskomnadzor“ bekannt, dass zwischen 2012 und 2017 rund 275000 Internetressourcen blockiert wurden, von denen 178000 danach wieder entsperrt wurden. ${ }^{93}$ Auch die russische Menschenrechtsorganisation

88 So das OG RF in Übersicht Rechtsprechungspraxis OG RF Nr. 2, 2018, Fn. 57, Punkt 42, S. 105.

89 Übersicht Rechtsprechungspraxis OG RF Nr. 2, 2018, Fn. 57, Punkt 42, S. 105.

90 Ein Anspruch auf gerichtlichen Rechtsschutz ergibt sich aus der allgemeinen Rechtsweggarantie in Art. 46 Abs. 2 VfRF und ihrer informationsrechtlichen Konkretisierung in Art. 8 Abs. 6 InfoG. Nach dieser Bestimmung können Entscheidungen und Tätigkeiten (Untätigkeit) von Staats- und kommunalen Organen, gesellschaftlichen Vereinigungen und Amtspersonen, welche das Recht auf Zugang zu Information einschränken, beim höherstehenden Organ bzw. der Amtsperson oder vor Gericht angefochten werden.

91 Dazu vorne III.1.a) und III.2.a).

92 Beanstandet wurde formell nicht das Monitoring der Sperrtätigkeit, sondern die auf der Website bereitgestellten Informationen über die Verschleierung von IP-Adressen. Die Blockierung der Website konnte verhindert werden, da „RosKomSvoboda“ die betreffenden Informationen freiwillig gelöscht hatte. Dazu https://www.interfax.ru/russia/494402, 15.1.2019.

93 Zur Statistik von „Roskomnadzor“ https://tass.ru/politika/4445476, 15.1.2019. 
„Agora“ legt ihrem periodischen Bericht zur Internetfreiheit in Russland die Zahlen von „Roskomnadzor" zugrunde. ${ }^{94}$ Nach Angaben von „RosKomSvoboda“ sind seit der Einführung des EReg im Jahr 2012 etwa 9 Millionen Internetressourcen blockiert worden, wobei hier auch die Eilsperren und die technisch bedingten Blockierungen dazugezählt werden. Näher bei den offiziellen Zahlen sind die Angaben von ,,antizapret“, wo von 444074 jemals im E-Reg eingetragenen Internetressourcen ausgegangen wird, von denen 311871 gelöscht worden sind (Stand: 15.1.2019). ${ }^{95}$ Nach Angaben auf ,usher" werden derzeit rund 3695886 IP-Adressen (Stand: 15.1.2019) blockiert. Eindeutig nachweisen lässt sich einzig die Tendenz zur massiven Zunahme der staatlichen Blockierungen von Internetressourcen in Russland, und zwar nach Angaben von „Roskomnadzor“ 72 Fälle der Sperre von URL im Jahr 2012 auf 88000 im Jahr 2017.96

\section{b) Ordentliches Verfahren}

Nach den offiziellen Angaben von „Roskomnadzor“ erfolgten die meisten Einträge im EReg im Zeitraum von 2012-2017 auf Grundlage von Gerichtsentscheidungen, in denen Internetressourcen für verboten befunden wurden. Danach folgen in absteigender Reihenfolge nach der Häufigkeit Online-Materialien zu den Themen Drogenpropaganda, Glücksspiele und Lotterien, Kinderpornographie sowie Informationen im Zusammenhang mit Suizid. ${ }^{97}$ Der Statistik bei ,antizapret“ lässt sich ebenfalls entnehmen, dass bisher die meisten Sperren auf Grundlage von Gerichtsentscheidungen erfolgt sind.$^{98}$ Ein Blick ins EReg auf https://antizapret.info/ und https://reestr.rublack list.net/ am 22. und 23. Dezember 2018 zeigt, dass an diesen zwei Tagen vor allem Websites im Zusammenhang mit Glücksspielen, Betrug (Fälschung von Zeugnissen und Diplomen, Manipulationen von Wärmezählern, Sozialversicherungsbetrug etc.), pornographischem Material und Websites betreffend den Ukrainekonflikt gesperrt wurden.

Im Rahmen des ordentlichen Verfahrens werden nach Angaben von „Roskomnadzor" 70 Prozent der beanstandeten Inhalte von den Website-Eigentümern freiwillig

94 Bericht der Menschenrechtsorganisation „Agora“ vom 5. Februar 2018 über die Internetfreiheit in Russland im Jahr 2017, http://www.agora.legal/articles/Doklad-Mezhdunarodnoi-Ag ory-\%C2\%ABSvoboda-interneta-2017-polzuchaya-kriminalizaciya $\% \mathrm{C} 2 \% \mathrm{BB} / 11$, 15.1.2019, S. 1, 20 (zit. Bericht „Agora“).

95 Vgl. dazu die Statistik auf https://antizapret.info/stat.php, 15.1.2019.

96 Dazu die offizielle Statistik von „Roskomnadzor" https://tass.ru/politika/4445476, 15.1.2019, wobei hier wiederum die Fälle der Sperre durch die GSA RF fehlen. А. Е. Кузьмин/А. В. Кульназарова, Анализ практики ограничения доступа к контенту в рунете со стороны органов государственной власти за 2014-2017 гг. (Kuz'min/Kul'nazarova, Analyse der Praxis der Beschränkung des Zugangs zu Content im Runet von Seiten der Staatsorgane von 2014 bis 2017), Вестник Омского университета. Серия „Исторические науки“ $3 \mid 2017$, S. 430 f. stellten im Zeitraum vom 1. Februar 2014 bis am 31. Mai 2017 ebenfalls eine starke Zunahme der Zahl an Sperren fest.

97 Dazu die Statistik von „Roskomnadzor“ aus dem Jahr 2017, abrufbar von https://tass.ru/pol itika/4445476, 15.1.2019.

$98 \mathrm{Vgl}$. die Grafik auf https://antizapret.info/stat.php, 15.1.2019. 
gelöscht und die Einträge danach aus dem EReg entfernt. ${ }^{99}$ Verbotene Online-Materialien werden auch über soziale Netzwerke, wie „ВКонтакте“ oder „Facebook“ verbreitet, wobei hier nach Angaben von „Roskomnadzor“ maßgeblich auf die Zusammenarbeit mit den verantwortlichen Administratoren gesetzt wird, welche die betreffenden Inhalte selbständig löschen. ${ }^{100}$ Dennoch werden in Russland einige soziale Netzwerke blockiert, so z. B. „Zello“, „Blackberry Messenger“, „Line“, „WeChat“ und seit 2016 aus Datenschutzgründen „Linkedin“. ${ }^{101}$ Auch der Kurznachrichtendienst „Telegram“ wird seit April 2018 in Russland (bisher erfolglos) blockiert, da dieser dem russischen Geheimdienst die Codes zur Entschlüsselung der Nachrichten nicht herausgeben wollte. „Roskomnadzor“ hat seit April 2018 Millionen von IPAdressen (u. a. von Google Accounts und Amazon-Diensten) blockiert, ohne dass dadurch die Funktionsfähigkeit von „Telegram“ nachhaltig beeinträchtigt worden wäre. ${ }^{102}$

Die Sperrpraxis gestützt auf Art. 15.1. InfoG wird in der russischen Lehre oft mit Hinweisen auf das der Sperre zugrundeliegende öffentliche Interesse in unkritischer Weise gutgeheißen. ${ }^{103}$ In der Praxis lassen sich allerdings etliche Schwächen im Umgang mit Art. 15.1. InfoG ausmachen. Zunächst geht es um die unglückliche Formulierung „информация о“ (,Information über“) in Art. 15.1. Abs. 5 Ziff. 1 InfoG, die v. a. zu Beginn der Sperrpraxis im Jahr 2013 zur Blockierung von Online-Enzyklopädien geführt hat. So wurde z. В. „Абсурдопедия (Absurdopedija)“ auf „Wikia“ wegen eines humorvollen Artikels zum Thema Suizid gesperrt, „Lurkmore“ und ,sportswiki.ru“ wegen Drogen-Propaganda. ${ }^{104}$ In ähnlicher Weise sperrte „Roskomnadzor“ zu Beginn die Resultate von Suchmaschinen, bis es seine Praxis in diesem Bereich anpasste. ${ }^{105}$

Ein weiteres Problem betrifft die beim Sperrverfahren auf Basis der Netzwerkadresse (IP-Adresse) technisch bedingte Blockierung weiterer Websites, welche mit der Zielwebsite eine Netzwerkadresse teilen. ${ }^{106}$ Die Sperre anhand der Netzwerk-

99 So seien bis 2017 bereits 178000 Einträge gelöscht worden https://tass.ru/politika/4445476, 15.1.2019. Zur Möglichkeit der freiwilligen Löschung der beanstandeten Information vorne III.1.c).

100 Dazu https://tass.ru/politika/4445476, 15.1.2019.

101 Bericht Freedom House 2018, Fn. 6; https://www.bbc.com/russian/news-37940028, 15.1.2019.

102 https://www.dw.com/ru/, 15.1.2019; vgl. Bericht Freedom House 2018, Fn. 6; zur Wirksamkeit der Online-Sperren hinten IV.7.

103 So z. B. bei Чаннов (С̆annov), Fn. 18, S. 86.

104 Dazu https://ria.ru/society/20131217/984701207.html; https://www.vedomosti.ru/technol ogy/articles/2012/11/12/lurkomore_vnesli_v_chernyj_reestr_sajtov_po_trebovaniyu_fsk $\mathrm{n}, 15.1 .2019$.

105 Vgl. Erläuterungen „Roskomnadzor“, Fn. 63.

106 Vgl. dazu die Statistik von „RosKomSvoboda“ zu den unrechtmäßig blockierten Websites auf https://antizapret.info/stat.php, 15.1.2019. Dieses Problem erwähnt auch K.В. Бородин, объекты и субъекты правового регулирования борьбы с распространением вредной информации в сети Интернет (Borodin, Objekte und Subjekte der rechtlichen Regulierung der Bekämpfung der Verbreitung von schädlicher Information im Internet), Информационное право 2|2016, S. 16. 
adresse ist in Art. 15.1. Abs. 9 und 10 InfoG vorgesehen. ${ }^{107}$ „Roskomnadzor“ hat sich eigentlich für die präzisere Sperrtechnik „IP+URL“ ausgesprochen, ${ }^{108}$ faktisch verfügen die Netzwerkbetreiber aber oft nicht über die (kostspieligen) technischen Vorrichtungen zur Umsetzung dieser Methode. ${ }^{109}$

Im Jahr 2013 wurde die Online-Bibliothek ,digital-books.ru“ gesperrt, da sie unter der gleichen Netzwerkadresse registriert war wie die wegen Drogen-Propaganda zu sperrende Website „http//rastaman.tales.ru/biblio/a k.htm“. Vladimir Charitonov, Eigentümer und Administrator von ,digital-books.ru“, focht die Sperre als unverhältnismäßige Einschränkung der Informations- und Meinungsfreiheit erfolglos beim Stadtbezirksgericht Taganskij in Moskau und danach beim Moskauer Stadtgericht an. ${ }^{110}$ Das von Charitonov angerufene Verfassungsgericht der RF trat mangels $\mathrm{Zu}-$ ständigkeit auf die Beschwerde nicht ein. ${ }^{111}$ Charitonov gelangte daraufhin an den EGMR und machte geltend, dass durch die unterschiedslose Blockierung von Websites durch die russischen Behörden sein Recht auf freie Meinungsäußerung in Art. 10 EMRK $^{112}$ verletzt werde. Daneben rügte er eine Verletzung des Rechts auf wirksame Beschwerde in Art. 13 EMRK, da die nationalen Gerichte seine Klage materiell nicht behandelt hätten. ${ }^{113}$ Im ähnlich gelagerten Fall Ahmet Ylldirım v. Turkey bejahte der EGMR angesichts der unterschiedslosen Blockierung (,indiscriminate blocking“) von Websites eine Verletzung von Art. 10 EMRK. ${ }^{114}$

107 Die Sperrtechnik kommt im Falle der Untätigkeit des Website-Eigentümers und des Hosting-Providers zur Anwendung. Dazu vorne III.1.c).

108 Vgl. Bericht „Rozkomnadzor“ Sperrtechniken, Fn. 37, S. 5 f.

109 Dazu https://www.novayagazeta.ru/articles/2017/09/15/73859-espch-sprosit-s-roskomnad zora-za-kasparov-ru, 15.1.2019. Auch die Registereinträge auf https://reestr.rublacklist.ne t/ und_https://antizapret.info/ zeigen, dass die Sperre nur anhand der IP-Adresse erfolgt und daneben keine URL aufgeführt sind.

110 Nach Auffassung beider Gerichte bestehe mit dem InfoG eine gesetzliche Grundlage zur Sperre auf Grundlage der IP-Adresse. Andererseits verfüge Charitonov als Beschwerdeführer über kein aktuelles Rechtsschutzinteresse, da der Eintrag zu „digital-books.ru“ inzwischen aus dem EReg gelöscht worden sei. Решение Таганского районного суда г. Москвы от 19 июня 2013 г. (Urteil des Stadtbezirksgericht Taganskij der Stadt Moskau vom 19.6.2013), N 2-1441/2013 (М-667/2013); Апелляционное определение Мосгорсуда от 12 сентября 2013 г. (Appellationsurteil des Moskauer Stadtgerichts vom 12.9.2013), N 11-29699/13.

111 Die Einschränkung der Informationsfreiheit erfolge durch den Hosting-Provider und betreffe deshalb lediglich das (zivilrechtliche) Rechtsverhältnis zwischen Website-Eigentümer und Hosting-Provider. Определение КС РФ от 17 июля 2014 г. (Beschluss des VfG RF vom 17.7.2014), N 1759-O/2014, E. 1, S. 2 f., E. 2 , S. 7.

112 Konvention zum Schutze der Menschenrechte und Grundfreiheiten vom 4. November 1950, SR/RS 0.101 .

113 EGMR, Vladimir Vladimirovich Kharitonov v. Russia, application no. 10795/14, http://hu doc.echr.coe.int/eng?i=001-173648, 15.1.2019.

114 Daneben verpflichtete der EGMR die Türkei zur Anpassung des zu weit formulierten nationalen Gesetzes zur Sperre von Internetressourcen. Ahmet Ylldirım v. Turkey, Urteil vom 18. Dezember 2012, application no. 3111/10, Para. 46 ff., http://hudoc.echr.coe.int/eng?i= 001-115705, 15.1.2019. 


\section{c) Eilsperre}

Nach Angaben von „RosKomSvoboda“ werden derzeit rund 12 Prozent (Stand: 15.1.2019) aller Internetsperren auf Initiative der GSA RF d. h. im Verfahren der Eilsperre vorgenommen. ${ }^{115}$ Offizielle Angaben zur Sperrpraxis von „Roskomnadzor“ im Bereich der Eilsperre fehlen. Eine Untersuchung der Sperrpraxis in den Jahren 2014-2017 zeigt, dass sich die blockierten Inhalte in diesem Zeitraum thematisch in absteigender Häufigkeit in vier Gruppen einteilen lassen, und zwar (1.) islamistische, (2.) oppositionelle, (3.) proukrainische und (4.) extremistisch-separatistische. ${ }^{116}$

Die Eilsperre in Art. 15.3. InfoG wurde seit ihrer Einführung im Jahr $2014 \mathrm{sehr}$ kontrovers diskutiert und die von der GSA RF verhängten Sperren oft gerichtlich angefochten. Besonders umstritten war die am 13. März 2014 angeordnete gleichzeitige Sperre des Blogs von Aleksej Naval'nyj im „Live Journal“ („Живой Журнал“), der Website des Oppositionsaktivisten, Garry Kasparov „Kasparov.ru“, des Online-Massenmediums „Грани.pу“ („Grani.ru“) sowie des Newsportals „ej.ru“ („Ежедневный Журнал“).

Der Zugang zum Internet-Blog von Naval'nyj im „Live Journal“ wurde auf Grundlage des Tatbestands des Aufrufs zur Teilnahme an gesetzeswidrigen (öffentlichen) Massenveranstaltungen in Art. 15.3. Abs. 1 InfoG eingeschränkt, da in zwei Posts mit Video- und Fotomaterial zu einer öffentlichen Versammlung vor dem Gericht aufgerufen wurde, das im „Bolotnaja-Prozess“ („Болотное дело“) geurteilt hatte. Die von Naval'nyj gegen die Sperre erhobene Beschwerde wurde vom Stadtbezirksgericht Ljublino in Moskau abgewiesen. ${ }^{117}$ Der Umstand, dass von der GSA RF die Sperre des gesamten Blogs und nicht nur der verbotenen Posts angeordnet wurde, erachtete das Gericht nicht als unverhältnismäßige Einschränkung der Meinungsfreiheit in Art. 29 Abs. 1 VfRF. Das gleiche gilt für die erst nachträglich erfolgte Konkretisierung der zu sperrenden Information durch die GSA RF. ${ }^{118}$ Das Stadtgericht von Moskau bestätigte die Entscheidung der Vorinstanz. ${ }^{19}$ Erst nachdem Naval'nyj nach eigenen Angaben sämtliche Posts in seinem Blog gelöscht hatte, wurde die Sperre aufgehoben. ${ }^{120}$ Danach weigerte sich der betreffende Hosting-Provider jedoch, den

$115 \mathrm{https} / / /$ reestr.rublacklist.net/visual/, 15.1.2019.

116 Dazu Кузьмин/Кульназарова (Kuz'min/Kul'nazarova), Fn. 96, S. 431.

117 Die Durchführung von öffentlichen Veranstaltungen auf Plätzen in unmittelbarer Nähe zu Gerichtsgebäuden sei nach Art. 8 Abs. 2 Ziff. 3 VersG verboten, weshalb der Aufruf den Tatbestand in Art. 15.3. Abs. 1 InfoG erfülle. Решение Люблинского районного суда города Москвы от 11 апреля 2014 г. (Urteil des Stadtbezirksgerichts Ljublino in Moskau vom 11.4.2014), N 2-3630/2014 (M-2439/2014).

118 Решение Люблинского районного суда города Москвы от 11 апреля 2014 г. (Urteil des Stadtbezirksgerichts Ljublino in Moskau vom 11.4.2014), N 2-3630/2014 (M-2439/2014). Die GSA RF ist nach Ziff. 36 VO ISZ verpflichtet, die zu sperrende Information genau zu bezeichnen. Dazu vorne III.2.c).

119 Апелляционное определение Мосгорсуда от 28 июля 2014 г. (Appellationsurteil des Moskauer Stadtgerichts vom 28.7.2014), N 33-28178.

$120 \mathrm{https} / / /$ navalny.com/p/4541/, 15.1.2019. 
Blog erneut aufzuschalten, weshalb Naval'nyj auf https://navalny.com/ einen neuen Blog einrichten musste. ${ }^{121}$

Im Fall von „Grani“ beanstandete die GSA RF einen Beitrag mit dem Titel „Auf dem Manezhnaja-Platz wurden die Teilnehmer einer Versammlung zur Unterstützung der Bolotnikov ${ }^{122}$ festgenommen“. Dieser enthalte einen Aufruf zur Teilnahme an gesetzeswidrigen Massenveranstaltungen, da die Handlungen der Versammlungsteilnehmer in einem positiven Licht dargestellt werden. ${ }^{123}$ Auch in diesem Fall bezeichnete die GSA RF die zu sperrende Information in ihrer Sperraufforderung nicht genau, sodass keine Möglichkeit zur freiwilligen Löschung derselben bestand. Das Stadtgericht von Moskau bestätigte das Urteil der Vorinstanz. ${ }^{124}$

Auf der Website des „Ежедневный Журнал“ wurde die Unterseite „Болотное дело“ („Bolotnaja-Prozess“) beanstandet, da darauf regelmäßig Material zu den Protestaktionen am 6. Mai 2012 veröffentlicht worden sei. Die Blockierung der Website wurde mit Urteil vom 12. August 2014 vom Moskauer Stadtbezirksgericht Tver' geschützt. ${ }^{125}$ Das gleiche gilt für die Facebook-Seite ,facebook.com/wwwejru“, wo die Informationen von ,www.ej.ru“ dupliziert wurden. Auch die (neben zahlreichen anderen) erstellte Kopie der Hauptwebsite „www.ej2015.ru“ wurde gesperrt. ${ }^{126}$ Der Zugang zur Website „Kasparov.ru“ wurde aufgrund eines Beitrags mit dem Titel „Auf der Krim wird das Staatseigentum nationalisiert" eingeschränkt. Dieser enthielt eine Abbildung von einem bewaffneten „Krim-Tataren“ und den folgenden Text: „Krim, wach auf! Die Okkupanten und ihre Diener stehlen dein Geld und verwüsten deine Städte! Ergibt dich nicht!“. Die GSA RF erblickte darin einen Aufruf zur Teilnahme an gesetzeswidrigen Massenveranstaltungen. Garry Kasparov focht die Sperre erfolglos beim Stadtbezirksgericht Chamovniki in Moskau ${ }^{127}$ und danach beim Stadtgericht von Moskau an. ${ }^{128}$ Die beanstandete Information wurde auch hier erst im Nachhinein konkretisiert. ${ }^{129}$

121 Zur „Selbstzensur“ („самоцензура“) der Hosting-Provider und Netzwerkbetreiber, die aus Angst vor Problemen mit den Staatsorganen in eigenem Ermessen problematische Inhalte löschen Терещенко (Tегеščenko), Fn. 18, S. 207 f.

122 Damit sind die Teilnehmer der Proteste auf dem „Bolotnaja-Platz“ am 6. Mai 2012 gemeint.

123 Решение Таганского районного суда города Москвы от 6 мая 2014 г. (Urteil des Stadtbezirksgerichts Taganskij in Moskau vom 6.5.2014), N 2-1343/2014 (M-1339/2014).

124 Апелляционное определение Московского городского суда от 2 сентября 2014 г. (Appellationsurteil des Moskauer Stadtgerichts vom 2.9.2014), N 33-18060/14.

125 Решение Тверского районного суда г. Москвы от 7 июля 2014 г. (Urteil des Stadtbezirksgerichts Tver' vom 7.7.2014), N 2-4793/2014 (M-4895/2014).

$126 \mathrm{https} / / /$ www.kommersant.ru/doc/3613498, 15.1.2019. Inzwischen wurde mit Art. 15.6. ${ }^{1}$ InfoG auch eine gesetzliche Grundlage zur Sperre von sog. „Spiegeln“ von verbotenen Websites geschaffen.

127 Решение Хамовнического районного суда г. Москвы от 6 августа 2014 г. (Urteil des Stadtbezirksgerichts Chamovniki vom 6.8.2014), N 2-2397/2014 (M-2249/2014).

128 Die Appellationsinstanz erblickte in der fraglichen Zeichnung und dem Text einen Aufruf zum organisierten Widerstand auf der Krim. Апелляционное определение Московского городского суда от 28 октября 2014 г. (Appellationsurteil des Moskauer Stadtgerichts vom 28.10.2014), N 33-36706.

129 In der Aufforderung der GSA RF wurden zuerst drei der in Art. 15.3. Abs. 1 InfoG erwähnten Tatbestände angeführt (Aufruf zu Massenunruhen, zur Ausübung extremistischer Tätigkeiten und zur Teilnahme an gesetzeswidrigen Massenveranstaltungen). „Rozkom- 
Gegen die Sperre von „Grani.ru“, „Kasparov.ru“, „ej.ru“ „, „RosKomSvoboda“130 sowie „Worldview of Russian Civilization“" wurden beim EGMR mehrere Beschwerden erhoben, die in der Sache OOO FLAVUS v. Russia vereint worden sind. ${ }^{131}$ Die Beschwerdeführer rügen eine Verletzung der in Art. 10 EMRK garantierten Meinungsäußerungsfreiheit durch die unterschiedslose und unrechtmäßige Blockierung (,indiscriminate and unwarranted blocking”) ihrer Websites. ${ }^{132}$ Im Fall von „RosKomSvoboda“ und „Worldview of Russian Civilization“ wird zusätzlich eine Verletzung des Rechts auf wirksame Beschwerde in Art. 13 EMRK geltend gemacht. In der vom EGMR angeordneten Stellungnahme erklärte Russland Ende März 2018, dass die Sperren der betreffenden Internetressourcen eine notwendige und verhältnismäßige Maßnahme im Interesse der nationalen Sicherheit, territorialen Integrität und öffentlichen Ordnung Russlands darstellen. ${ }^{133}$

\section{Probleme aus verfassungsrechtlicher Sicht}

\section{Ausgangspunkt: Informations- und Kommunikationsgrundrechte}

Durch die beiden zuvor skizzierten Verfahren zur staatlichen Sperre von Internetressourcen werden die Meinungsäußerungs- (Art. 29 Abs. 1 VfRF), Informations(Art. 29 Abs. 4 VfRF) und Medienfreiheit (Art. 29 Abs. 5 Satz 1 VfRF) sowie allenfalls das Zensurverbot (Art. 29 Abs. 5 Satz 2 VfRF) tangiert. Die Verbreitung von Informationen über das Internet fällt in den sachlichen Schutzbereich der Garantien in Art. $29 \mathrm{VfRF}$, da diese Informationen bzw. Meinungsäußerungen unabhängig von ihrem Verbreitungsweg erfassen. ${ }^{134}$ Die in Art. 29 Abs. 4 VfRF garantierte Informationsfreiheit wird in Art. 8 Abs. 1 InfoG konkretisiert. Das Zensurverbot kommt - als Bestandteil der Medienfreiheit - auch auf registrierte Online-Massenmedien zur An-

nadzor" beschränkte den Sperrgrund dann nachträglich auf die Aufforderung zur Teilnahme an gesetzeswidrigen Massenveranstaltungen. Апелляционное определение Московского городского суда от 28 октября 2014 г. (Appellationsurteil des Moskauer Stadtgerichts vom 28.10.2014), N 33-36706.

130 Zur Aufnahme von „RosKomSvoboda“ ins EReg im Jahr 2016 vorne III.4.a).

131 EGMR, OOO FLAVUS v. Russia, Application no. 12468/15, http://hudoc.echr.coe.int/eng? $\mathrm{i}=001-177236,15.1 .2019$.

132 Dabei war problematisch, dass die GSA RF die beanstandete Information in ihrer Sperraufforderung nicht genau bezeichnet hatte, sodass die Information nicht freiwillig gelöscht und damit die Wiederherstellung des Zugangs zur Ressource begünstigt werden konnte. Bei "RosKomSvoboda" wird geltend gemacht, dass die Aufschaltung von Informationen betreffend Techniken zur Anonymisierung im Internet nicht unrechtmäßig sei. Dazu vorne III.4.a), c).

$133 \mathrm{https} / /$ www.vedomosti.ru/politics/articles/2018/03/28/755098-vnesudebnuyu-blokirovku -saitov, 15.1.2019.

134 Zum sachlichen Anwendungsbereich der Garantien in Art. 29 VfRF Von Gall, Fn. 22, N 23 , 45, 56 ff.; Казаниев (Kazancev), Fn. 12, S. 276 f.; Л.В. Лазарев, in: Ders. (Hrsg.), Комментарий к Конститиции Российской Федерации (Lazarev, Kommentar zur Verfassung der RF), Art. 29 VfRF, 3. Aufl., Moskau 2009, S. 160. 
wendung. ${ }^{135}$ Der Anwendungsbereich der Garantien in Art. 29 VfRF überschneidet sich, ${ }^{136}$ weshalb in der Rechtsprechungspraxis im Zusammenhang mit der Blockierung von Online-Inhalten oftmals mehrere Garantien parallel angerufen werden. ${ }^{137}$ Auch der Schutzbereich der in Art. 10 EMRK garantierten Kommunikationsfreiheiten sowie derjenigen in Art. 19 IPBPR $^{138}$ ist eröffnet. ${ }^{139}$

Einschränkungen der in Art. $29 \mathrm{VfRF}$ garantierten Kommunikationsgrundrechte sind nur unter den Voraussetzungen von Art. 55 Abs. 3 VfRF (föderales Gesetz, Eingriffszweck, Verhältnismäßigkeit) ${ }^{140}$ bzw. Art. 9 InfoG zulässig. ${ }^{141}$ Diese Voraussetzungen entsprechen den im Bericht des UN-Sonderbeauftragten für Meinungsfreiheit aufgestellten Anforderungen an die Einschränkungen der Meinungsäußerungsfreiheit im Internet. ${ }^{142}$ Zudem ist die Schrankenbestimmung in Art. 29 Abs. 2 VfRF (Propaganda- und Agitationsverbot) ${ }^{143}$ sowie das Gebot der Achtung des Schutzes von Grundrechten Dritter in Art. 17 Abs. 3 VfRF zu beachten. ${ }^{144}$ Die formell-gesetzliche Grundlage zur Einschränkung der Kommunikationsfreiheiten im Internet liegt mit Art. 15.1. und Art. 15.3. InfoG regelmäßig vor. Die Online-Sperren verfolgen zudem - zumindest vordergründig - Motive (Schutz der öffentlichen Sicherheit und Ordnung

135 Es wird in Art. 3 MedienG folgendermaßen definiert: ,,eine Aufforderung von Amtspersonen, Staatsorganen, Organisationen, Einrichtungen oder gesellschaftlichen Verbänden an die Redaktion eines Massenmediums, Nachrichten und Materialien vorgängig zu vereinbaren (es sei denn die Amtsperson sei Autor oder interviewte Person) oder die Auferlegung von Verboten zur Verbreitung von Nachrichten und Materialien oder einzelner Teile davon".

136 Das Verhältnis der Garantien in Art. 29 VfRF ist unklar. Казанцев (Kazancev), Fn. 12, S. 268; von Gall, Fn. 22, N 11.

137 So berief man sich im Fall von „Grani“ auf die Meinungsäußerungs- und Medienfreiheit in Art. 29 Abs. 1 bzw. Art. 29 Abs. 5 Satz 1 VfRF. Vgl. Апелляционное определение Московского городского суда от 2 сентября 2014 г. (Appellationsurteil des Moskauer Stadtgerichts vom 2.9.2014), N 33-18060/14.

138 Internationaler Pakt über bürgerliche und politische Rechte vom 16. Dezember 1966, SR/RS 0.103.2.

139 Zum sachlichen Schutzbereich der Kommunikationsgrundrechte in Art. 10 EMRK $C h$. Grabenwarter/K. Pabel, Europäische Menschenrechtskonvention, 6. Aufl., München 2016, $\S 23$. Politische und gemeinschaftsbezogene Grundrechte, Rn. $1 \mathrm{ff}$. Zu den Garantien in Art. 10 EMRK und Art. 19 IPBPR im Verhältnis zu Art. 29 VfRF Казанчев (Kazancev), Fn. 12, S. 269 f.; Шленева (Šleneva), Fn. 74, S. 132 f.

$140 \mathrm{Zu}$ den Voraussetzungen von Grundrechtseinschränkungen im Allgemeinen R. Arnold/A. Berger, Kommentar zu Art. 55 VfRF, in: B. Wieser (Hrsg.), Handbuch der russischen Verfassung, Wien 2014, N $12 \mathrm{ff}$.

141 Чаннов (Cannov), Fn. 18, S. 83 f.; Казанчев (Kazancev), Fn. 12, S. 270 f

142 Die Einschränkungen müssen gesetzlich vorgesehen und verhältnismäßig sein sowie einen legitimen Eingriffszweck verfolgen. Report of the Special Rapporteur on the promotion and protection of the right to freedom of opinion and expression of August 10, $2011 \mathrm{Nr}$. A/ 66/290, Ziff. 15 (zit. Report SR UN), https://www.ohchr.org/EN/Issues/FreedomOpinion/ Pages/Annual.aspx, 15.1.2019.

143 Dabei handelt sich nicht um eine Ausnahme vom Schutzbereich, sondern eine Schranke, die der Rechtfertigung unterliegt. Von Gall, Fn. 22, N 42. Das Verbot in Art. 29 Abs. 2 VfRF erstreckt sich nach Казанцев (Kazancev), Fn. 12, S. 271 f. auf sämtliche Garantien in Art. 29 VfRF.

144 Шленева (Šleneva), Fn. 74, S. 134; Казанчев (Kazancev), Fn. 12, S. 272. 
sowie Moral), die sich aus Art. 55 Abs. 3 VfRF ergeben. ${ }^{145}$ In der Sperrpraxis bereitet vor allem das Erfordernis der Verhältnismäßigkeit der Internetsperren Probleme. ${ }^{146}$

\section{Unterschiedslose Blockierung}

Grundsätzlich besteht sowohl beim ordentlichen Verfahren (vgl. Art. 15.1. Abs. 2 Ziff. 1 InfoG) ${ }^{147}$ als auch bei der Eilsperre (vgl. Art. 15.3. Abs. 3 InfoG) ${ }^{148}$ die Möglichkeit der gezielten Blockierung von Online-Inhalten, indem einzelne Internetseiten und nicht nur ganze Websites gesperrt werden können. „Roskomnadzor“ hat sich denn auch zur Sperrtechnik „IP+URL“ bekannt. ${ }^{149}$

Dennoch erfolgen Sperren von Online-Inhalten in der Praxis oft in undifferenzierter Weise auf Grundlage der Netzwerkadresse, da die Internet-Provider oder Netzwerkbetreiber nicht über die (kostspieligen) technischen Vorrichtungen zur Blockierung einzelner Internetseiten verfügen ${ }^{150}$ Dadurch kann es zur Blockierung unbeteiligter Websites kommen, welche mit der Ziel-Website eine Netzwerkadresse teilen, so z. B. bei digitalbooks.ru. ${ }^{151} \mathrm{Im}$ Fall des Kurznachrichtendiensts „Telegram“ wurden durch „Roskomnadzor" mehrere Millionen IP-Adressen gesperrt, wodurch zahlreiche unbeteiligte Websites mit der gleichen IP-Adresse blockiert wurden. ${ }^{152}$ Nach Anga-

145 In Art. 55 Abs. 3 VfRF werden folgende Zwecke von Grundrechtseinschränkungen genannt: Schutz der Grundlagen der Verfassungsordnung, der Moral, der Gesundheit, der Rechte und gesetzlichen Interessen Dritter, der Gewährleistung der Landesverteidigung sowie der Staatssicherheit.

146 Das Erfordernis der Verhältnismäßigkeit verlangt, dass der Grundrechtseingriff im Verhältnis zum Eingriffsziel geeignet, erforderlich und zumutbar ist. $\mathrm{Zu}$ fordern ist, dass kein milderes (ebenso geeignetes) Mittel zur Verfügung steht und Eingriffszweck und Ziel in einem angemessenen Verhältnis stehen. Dazu Arnold/Berger, Fn. 140, N 28.

147 Der Website-Eigentümer wird zuerst nur zur Löschung der jeweiligen Internetseite, nicht aber der ganzen Website aufgefordert (Art. 15.1. Abs. 7 InfoG). Subsidiär erfolgen dann die Einschränkung des Zugangs zur gesamten Website durch den Hosting-Provider und als ultima ratio die Sperrung der Netzwerkadresse durch den Netzwerkbetreiber. Zum Ablauf des Sperrverfahrens vorne III.1.c).

148 Der Netzwerkbetreiber ist nach Art. 15.3. Abs. 3 InfoG verpflichtet, den Zugang zur Internetressource, ,,u. a. der Website“ („в том числе к сайту в сети интернет“) mit der verbotenen Information zu sperren. Zum Ablauf des Sperrverfahrens vorne III.2.c).

149 Dazu vorne III.

150 Терешенко (Tereščenko), Fn. 18, S. 206 f.; Чаннов (С̌annov), Fn. 18, S. 87. Dazu auch der Artikel auf https://www.novayagazeta.ru/articles/2017/09/15/73859-espch-sprosit-s-rosko mnadzora-za-kasparov-ru, 15.1.2019. In einem vom OG RF zu beurteilenden Fall machte ein Netzwerkbetreiber gegenüber der Staatsanwaltschaft der Stadt Chabarovsk die fehlenden technischen Möglichkeiten zur Sperre einzelner Webseiten geltend und verweigerte gestützt darauf die Blockierung des auf der Website zu sperrenden extremistischen Inhalts. Das OG RG verpflichtete den Netzwerkbetreiber zur Sperre der gesamten Website. Dazu Определение Верховного Суда РФ от 10 мая 2011 г. (Beschluss des OG RF vom 10.5.2011), N 58-Впр11-2 (Бюллетень Верховного Суда РФ N 12 от 30 декабря 2011 г.) (Bulletin des OG RF Nr. 12, 30.12.2011).

151 Dazu vorne III.4.b).

152 Dabei trugen die betreffenden Unternehmen Einbußen und einen Reputationsschaden davon. Dazu https://www.dw.com/ru/, 15.1.2019. 
ben von „RosKomSvoboda“ werden 67,5 Prozent der Internetressourcen (Stand: 15.1.2019) rein technisch bedingt durch die Sperre auf Grundlage der Netzwerkadresse blockiert. ${ }^{153}$

Zum anderen wurde v. a. in der Praxis zur Eilsperre von der GSA RF bewusst die Blockierung der gesamten Website angeordnet, so im Gutachten der GSA RF vom 12. März 2014 betreffend die Sperre des Blogs von Naval'nyj sowie „Grani.ru“, „Kasparov.ru“ und „ej.ru“. Die Begründung dafür war, dass der Anteil an rechtswidrigen Informationen im Verhältnis zum Umfang des übrigen Materials wesentlich sei. ${ }^{154}$ Eine derartige Sperrpraxis ist unverhältnismäßig, da erstens mit der gezielten Sperrtechnik „IP+URL“ ein milderes Mittel zur Verfügung stehen würde und zweitens der Eingriff und seine Nebeneffekte (Sperre zahlreicher Websites ohne gesetzeswidrige Inhalte) über den angestrebten Zweck (Sperre einer einzelnen Website zur Wahrung der öffentlichen Sicherheit und Ordnung) hinausgeht.

\section{Unbestimmte Eingriffsgrundlage}

Die Eingriffstatbestände in Art. 15.3. Abs. 1 InfoG sind offen formuliert, so z. B. der Aufruf zu Massenunruhen oder die extremistische Tätigkeit, die sich nach dem schwammigen Extremismusbegriff in Art. 1 ExtrG richtet. ${ }^{155}$ Die Sperrpraxis zeigt, dass über die offen formulierten Eingriffstatbestände politisch motivierte Sperren von oppositionellen Internetinhalten erfolgen, so beispielsweise betreffend Information im Zusammenhang mit dem Ukraine-Konflikt. ${ }^{156}$

Dazu kommt der Umstand, dass die GSA RF die beanstandete Information in ihren Sperraufforderungen entgegen Ziff. 36 VO ISZ oft nicht genau bezeichnet und die Sperre auch nicht in nachvollziehbarer Weise begründet. ${ }^{157} \mathrm{Im}$ Gutachten der GSA RF vom 12. März 2014 zur Sperre des Blogs von Naval'nyj sowie „Grani.ru“, „Kasparov.ru“ und „ej.ru“ wurde pauschal die „gemeinsame thematische Ausrichtung“ („единая тематическая направленность“) der Internetressourcen beanstandet. ${ }^{158}$ Durch die ungenaue Bezeichnung des zu sperrenden Inhalts von staatlicher

153 Vgl. https://reestr.rublacklist.net/visual/, 15.1.2019.

154 Hinweise auf das Gutachten der GSA RF vom 12. März 2014 enthalten Апелляционное определение Московского городского суда от 2 сентября 2014 г. (Appellationsurteil des Moskauer Stadtgerichts vom 2.9.2014), N 33-18060/14 sowie Решение Таганского районного суда города Москвы от 6 мая 2014 г. (Urteil des Stadtbezirksgerichts Taganskij in Moskau vom 6.5.2014), N 2-1343/2014 (M-1339/2014).

155 Auch die Venedig-Kommission hatte den Extremismusbegriff als konturenlos kritisiert (Opinion Nr. 660/2011 vom 20. Juni 2012, CDL-AD 2012/016, Ziff. 30 ff.). Zur Problematik des Extremismusbegriffs im Zusammenhang mit der Pressefreiheit C. Schmidt, Der Journalist, ein potentieller „Extremist“ - der russische Extremismusbegriff seit Juli 2006, Osteuropa-Recht 5-6|2006, S. 409 ff. Zum Extremismusbegriff vorne III.2.b).

156 Dazu vorne III.4.c).

157 Vgl. Bericht Freedom House 2018, Fn. 6.

158 Das Gutachten der GSA RF wird zitiert in Решение Таганского районного суда города Москвы от 6 мая 2014 г. (Urteil des Stadtbezirksgerichts Taganskij in Moskau vom 6.5.2014), N 2-1343/2014 (M-1339/2014). Vgl. Апелляционное определение Московского городского суда от 28 октября 2014 г. (Appellationsurteil des Moskauer Stadtgerichts vom 28.10.2014), N 33-36706. 
Seite werden die Netzwerkbetreiber zur „Selbstzensur“ ermächtigt, die aus Angst vor Konflikten mit den Behörden großzügig Webinhalte in Eigenregie sperren. ${ }^{159}$ Eine derartige Sperrpraxis räumt der GSA RF und zuletzt auch Dritten bei der Sperre von Online-Inhalten großes Ermessen ein, was der Vorhersehbarkeit des Verwaltungshandels und der Rechtssicherheit abträglich ist.

\section{Verfahrenslücken}

Trotz Konkretisierung in Verordnungen und Erlassen der Exekutivorgane des Bundes weisen die Sperrverfahren in Art. 15.1. und Art. 15.3. InfoG zahlreiche Lücken auf, was „Roskomnadzor" beim Vollzug einen großen Ermessensspielraum einräumt. So wird beispielsweise im Fall eines Gesuchs um Wiederherstellung des Zugangs zur Internetressource nach Art. 15.3. Abs. 5 und 6 InfoG die Frist zur Überprüfung der Löschung der beanstandeten Information durch „Roskomnadzor" nicht bestimmt. ${ }^{160} \mathrm{Die}$ Internet-Ressource bleibt für die Dauer der Überprüfung gesperrt, was für die betreffenden Website-Eigentümer Rufschäden und wirtschaftliche Einbußen zur Folge haben kann. ${ }^{161}$

Ähnliches gilt betreffend die Überprüfung der in der Sperranfrage der GSA RF angegebenen Online-Informationsressource auf das Vorhandensein von verbotenen Informationen durch „Roskomnadzor“" nach Ziff. 37 VO ISZ. ${ }^{162}$ Aus der genannten Bestimmung ergibt sich nicht, wie „Roskomnadzor“ vorzugehen hat, wenn die beanstandete Informationsressource keine verbotenen Informationen enthält. Es ist anzunehmen, dass die Sperre der Online-Ressource dennoch vorgenommen werden muss, da „Roskomnadzor“" nicht das Recht hat, sich der Anordnung der GSA RF zu widersetzen. ${ }^{163}$

\section{Außergerichtliche Sperre}

Weder das ordentliche Verfahren noch die Eilsperre setzen zur Blockierung von Internetressourcen eine gerichtliche Entscheidung voraus. ${ }^{164}$ Nach Art. 15.1. Abs. 2 EReg

159 Vgl. Bericht Freedom House 2018, Fn. 6; Терещенко (Tereščenko), Fn. 18, S. 207 f. Dazu vorne III.4.c).

$160 \mathrm{Zu}$ diesem Verfahrensschritt vorne III.2.c).

161 In diesem Zusammenhang wurden wettbewerbsrechtliche Bedenken im Hinblick auf die beiden Sperrverfahren angemeldet. Die sowohl im ordentlichen Verfahren als auch der Eilsperre vorgesehenen Eingaben und Meldungen Privater können zur Behinderung unliebsamer Konkurrenten eingesetzt werden. Vgl. В.В. Бояркин/Л.А. Бояркина, Цензура в интернете: полгода спустя (Bojarkin/Bojarkina, Internetzensur: ein halbes Jahr später), Гаудеамус (Gaudeamus) 2|2013, S. 145 f. Zu den Eingaben und Meldungen vorne III.1.c) und III.2.c).

$162 \mathrm{Zu}$ diesem Verfahrensschritt vorne III.2.c).

163 Sо Савельев (Savel'ev), Fn. 24, Art. 15.3. InfoG (zitiert nach der Datenbank „Consultant Plus").

164 Kritisch Д.Е. Петров, Ограничение распространения информации в сети интернет (Petrov, Einschränkung der Verbreitung von Information im Internet), Юридический мир 1|2012, S. 33. 
bildet eine Gerichtsentscheidung (neben der Entscheidung des zuständigen föderalen Exekutivorgans) lediglich eine mögliche Grundlage zur Aufnahme einer Internetressource ins EReg. ${ }^{165}$ Mit Inkrafttreten von Art. 14 Änderungsgesetz Nr. 451-FZ wird nicht einmal mehr die Rechtskraft der Gerichtsentscheidung vorausgesetzt. Verschärft wird die Situation durch die zeitliche Straffung des ordentlichen Verfahrens im Änderungsgesetz Nr. 472-FZ, wodurch Websites unmittelbar auf Grundlage der Entscheidung des zuständigen föderalen Exekutivorgans gesperrt werden können. Bei der Eilsperre ordnet die GSA RF und nicht eine richterliche Behörde die Blockierung an; lediglich die Aufhebung der Sperre kann auf richterliches Urteil hin erfolgen. ${ }^{166}$

Der Beschwerde gegen die Blockierung von Online-Inhalten nach Art. 15.1. oder Art. 15.3. InfoG kommt i. d. R. keine aufschiebende Wirkung zu, ${ }^{167}$ weshalb die betreffende Online-Ressource auch während des Beschwerdeverfahrens gesperrt bleibt. Im Fall von registrierten Online-Massenmedien kommt dies einer Einstellung der Tätigkeit des betreffenden Massenmediums gleich (z. B. im Fall von „Grani.ru“), welche nach Art. 16 Abs. 1 MedienG eigentlich nur auf Grundlage einer Entscheidung des Gründers eines Massenmediums oder einer Gerichtsentscheidung erfolgen dürfte. ${ }^{168}$

\section{Mangelnde Transparenz und Zugänglichkeit}

Weder das EReg noch das „Register von Lugovoj“ können von gewöhnlichen Internetnutzern ohne weiteres eingesehen werden. ${ }^{169}$ Unter „https://eais.rkn.gov.ru/“ bzw. „http://398-fz.rkn.gov.ru/“_steht lediglich eine Suchfunktion zur Verfügung, mit der überprüft werden kann, ob sich eine bestimmte Website, Internetseite oder Netzwerkadresse in den Registern befindet. Dies macht das staatliche Sperrverfahren für den Einzelnen wenig transparent und inoffizielle Statistiken und Portale (,RosKomSvoboda“, ,antizapret" oder ,usher“) gewinnen an Bedeutung, da sie den Inhalt der Register offenlegen. ${ }^{170}$

Problematisch ist auch die Unübersichtlichkeit der zahlreichen Register, Untersysteme und dazugehörigen Rechtsgrundlagen. ${ }^{171}$ Abhilfe schaffen soll der neue „Universale Dienst zur Überprüfung der Einschränkung des Zugangs zu Websites und

$165 \mathrm{Zu}$ den Aufnahmegründen vorne III.1.b).

$166 \mathrm{Im}$ Gegensatz dazu setzt die Aufnahme in die föderale Liste extremistischer Materialien in Art. 13 ExtrG die Entscheidung eines föderalen Gerichts voraus. Dazu vorne II.1.

167 Dazu vorne III.3.

168 Тигранян (Tigranjan), Fn. 14, S. 146. So auch Определение Верховного Суда РФ от 16 июля 2014 г. (Beschluss des OG RF vom 16.7.2014), N 3-AПГ 14-1, S. 3 f.

$169 \mathrm{Zu}$ den speziellen Zugangsrechten für bestimmte Organe und Personen vorne III.1.a).

170 Кузьмин/Кульназарова (Киз'min/Kul'nazarova), Fn. 96, S. 430. Zu diesen Portalen vorne III.4.a).

171 So existieren neben dem EReg und dem „Register von Lugovoj“ vier weitere SperrRegister, und zwar im Zusammenhang mit Urheberrechtsverletzungen (Art. 15.2 und 15.6 InfoG), „Nachrichten-Aggregatoren“ (Art. 10.4. InfoG), audiovisuellen Diensten (Art. 10.5. InfoG) und Informationsressourcen oder Systemen, die den Zugang zu verbotenen Inhalten ermöglichen (Art. 15.8. InfoG). Vgl. dazu die Übersicht von „Roskomnadzor“ auf https:// rkn.gov.ru/mass-communications/p753/, 15.1.2019. 
(oder) Internetseiten“ auf http://blocklist.rkn.gov.ru/, der eine einheitliche Anfrage für den Inhalt sämtlicher Register vorsieht.

\section{Wirksamkeit}

Wurde der Zugang zu einer Internetressource eingeschränkt, wird der Internetnutzer sowohl beim ordentlichen Verfahren als auch der Eilsperre zu einer Sperrmeldung von „Roskomnadzor" weitergeleitet. Die Blockierung wirkt allerdings nur für Nutzer mit einer russischen IP-Adresse, sodass die Websites von anderen Ländern aus i. d. R. abrufbar bleiben. Weiterhin kann die Sperre auch von russischen Internetnutzern umgangen werden, z. B. durch Programme, welche die Herkunft der IP-Adresse verschleiern (sog. „Anonymizer"), Internet-Browser mit entsprechender Wirkung oder VPN-Technologien. ${ }^{172}$

Die Wirksamkeit der Sperrmaßnahmen von „Roskomnadzor" wird jedoch auch innerhalb des „Runet“ angezweifelt. In diesem Jahr wurde dies v. a. im Zusammenhang mit der Sperre des Kurznachrichtendienst „Telegram“ deutlich, der weiterhin funktioniert, obwohl „Roskomnadzor" Millionen von IP-Adressen blockiert hat. ${ }^{173}$ Ähnliches gilt für die permanente, jedoch wenig effektive Sperre des Torrent-Trackers „RuTracker“. ${ }^{174}$ Die russische Menschenrechtsorganisation „Agora“ geht in ihrem Bericht davon aus, dass zwei Drittel der staatlich blockierten Internetressourcen weiterhin funktioniert und der Anteil an schädlichen Internet-Inhalten insgesamt nicht effektiv reduziert werden konnte. ${ }^{175}$ Die geringe Wirksamkeit der Sperren von „Roskomnadzor" lässt Zweifel an deren Eignung aufkommen.

\section{Zusammenfassende Würdigung und Ausblick}

Seit dem Jahr 2012 wurde in Russland das rechtliche Instrumentarium zur staatlichen Blockierung von Internetinhalten durch Änderungen des InfoG (v. a. Art. 15.1.-15.8. InfoG) gesetzgeberisch stark erweitert und - je nach Inhalt der zu sperrenden Information - unterschiedliche Sperrverfahren geschaffen. Der föderale Gesetzgeber stützt sich dabei auf Art. 71 Bst. „И“ VfRF sowie spezialgesetzliche Verfassungsgrundlagen. Die regionalen und kommunalen Gesetzgeber konkretisieren die föderalen Bestimmungen v. a. im Bereich der regionalen und lokalen Informationssysteme. ${ }^{176}$

Aus verfassungsrechtlicher Sicht bedeutsam sind insbesondere das ordentliche Sperrverfahren in Art. 15.1. InfoG und die Eilsperre in Art. 15.3. InfoG. Herzstück des ordentlichen Verfahrens ist das EReg, das der Identifizierung von Internetressour-

172 Vgl. https://www.rbc.ru/technology_and_media/16/02/2017/588619a59a79473089dbad6 9, 15.1.2019.

173 https://www.dw.com/ru/-----telegram/a-44768136, 15.1.2019.

174 Vgl. https://www.rbc.ru/technology and media/22/01/2016/56al f93d9a79477fe $1874 \mathrm{e} 0 \mathrm{e}$; https://www.rbc.ru/technology_and_media/31/01/2016/56ab56b09a79477c28de67fb, 15.1.2019.

175 Bericht „Agora“, Fn. 94, S. 16.

176 Dazu vorne II. 
cen dient, welche Informationen enthalten, die zuvor vom zuständigen föderalen Exekutivorgan oder einem Gericht für verboten befunden worden sind. Dem Eigentümer der betreffenden Website wird im ordentlichen Verfahren Gelegenheit gegeben, die beanstandeten Informationen freiwillig zu löschen, bevor der Zugang zur Website auf Anordnung von „Roskomnadzor“ hin blockiert wird. ${ }^{177} \mathrm{Im}$ Verfahren der Eilsperre nach Art. 15.3. InfoG erfolgt die Blockierung der Online-Informationsressource dagegen umgehend auf Anordnung der GSA RF hin. ${ }^{178}$ Bei beiden Verfahren besteht die Möglichkeit, die Wiederherstellung des Zugangs zur Informationsressource zu verlangen und die Sperren gerichtlich anzufechten.

Da der Inhalt des EReg und des „Registers von Lugovoj“ für gewöhnliche Internetnutzer nicht frei zugänglich ist, kommt inoffiziellen Statistiken über die Sperrpraxis von „Roskomnadzor“ große Bedeutung zu. Die Angaben über die Anzahl an gesperrten Internetressourcen weichen stark voneinander ab. Einzig die Tendenz zur massiven Zunahme der Zahl an Internet-Sperren ab 2012 lässt sich klar nachweisen. ${ }^{179} \mathrm{Im}$ ordentlichen Verfahren werden die meisten Internetressourcen auf Grundlage von Gerichtsentscheidungen sowie Entscheidungen der föderalen Exekutivorgane in den Bereichen Glücksspiele und Drogen blockiert. Von der Eilsperre werden insbesondere islamistische und oppositionelle Materialien erfasst, jedoch fehlen offizielle Angaben zur Sperrpraxis. ${ }^{180}$

Durch die Sperre von Internetressourcen im ordentlichen Verfahren (Art. 15.1. InfoG) und der Eilsperre (Art. 15.3. InfoG) werden die Informations- und Kommunikationsgrundrechte in Art. 29 VfRF, Art. 10 EMRK und Art. 19 IPBPR tangiert. Einschränkungen derselben sind nur unter den Voraussetzungen von Art. 55 Abs. 3 VfRF (Art. 10 Abs. 2 EMRK, Art. 19 Abs. 3 IPBPR) zulässig und verlangen eine gesetzliche Grundlage, ein zulässiges Eingriffsmotiv und die Verhältnismäßigkeit des Eingriffs. ${ }^{181}$

Die Sperrpraxis zu Art. 15.1. und Art. 15.3. InfoG macht deutlich, dass die staatlichen Blockierungen von Online-Ressourcen den genannten Eingriffsvoraussetzungen nicht immer standhalten. Die formell-gesetzliche Eingriffsgrundlage ist mit dem InfoG zwar gegeben, jedoch erscheinen die Vorschriften oftmals zu wenig bestimmt und lückenhaft, weshalb „Roskomnadzor" bei der Sperre von Online-Inhalten ein weiter Ermessensspielraum zukommt. ${ }^{182}$ Auch die Eingriffsmotive sind - wie die Sperrpraxis zeigt - bei der Sperre von oppositionellen Online-Medien, unerwünschten Blogs, Kurznachrichtendiensten oder Online-Enzyklopädien zweifelhaft. Die meisten Probleme bereitet allerdings das Erfordernis der Verhältnismäßigkeit. Die Sperren von „Roskomnadzor“ sind in der Praxis oft wirkungslos (z. B. die Blockierung von „Telegram“), was Zweifel an deren Eignung aufkommen lässt. ${ }^{183}$ Weiterhin werden Websites in der Praxis oft auf Grundlage der Netzwerkadresse blockiert, obwohl mit der Sperrtechnik „IP+URL“ ein milderes Mittel zur Verfügung stehen würde. Auch die

177 Dazu vorne III.1.

178 Dazu vorne III.2.

179 Dazu vorne III.4.a).

180 Dazu vorne III.4.b) und c).

181 Dazu vorne IV.1.

182 Dazu vorne IV.4.

183 Dazu vorne IV.7. 
Sperre der gesamten Website anstelle einzelner Internetseiten erscheint nicht erforderlich. ${ }^{184}$ Das gleiche gilt für die Praxis der GSA RF, in der Sperraufforderung die beanstandete Information entgegen Ziff. 36 VO ISZ nicht genau zu bezeichnen. ${ }^{185}$ Die außergerichtlich angeordnete faktische Einstellung der Tätigkeit von Online-Massenmedien verstößt gegen Art. 16 MedienG. ${ }^{186}$ Das rigide Vorgehen gegen oppositionelle Online-Massenmedien (faktisch unbegrenzte Sperre bei „Grani.ru“) erfüllt allenfalls sogar den Tatbestand des verfassungsrechtlichen Zensurverbots in Art. 29 Abs. 5 Satz 2 VfRG i. V. m Art. 3 MedienG.

Vor diesem Hintergrund sind den beiden derzeit beim EGMR hängigen Beschwerden Kharitonov v. Russia und OOO FLAVUS v. Russia gute Erfolgschancen einzuräumen. Es ist anzunehmen, dass der EGMR in der unterschiedslosen Blockierung von Internetressourcen analog dem Fall Ahmet Ylldirlm v. Turkey eine Verletzung von Art. 10 EMRK annehmen und dabei auf die Notwendigkeit der Konkretisierung der unbestimmten Vorschriften im InfoG hinweisen wird. ${ }^{187}$ Im Fall OOO FLAVUS $v$. Russia könnte der EGMR eine Verletzung von Art. 10 EMRK darin erblicken, dass anhand der Sperraufforderung der GSA RF nicht erkennbar war, welche Inhalte auf den betreffenden Websites beanstandet wurden. Dadurch bestand keine Möglichkeit zur eigenständigen Löschung der Informationen, wodurch die Wiederherstellung des Zugangs zu den betreffenden Websites verzögert bzw. gar verunmöglicht wurde. ${ }^{188}$

Zur Verbesserung seiner Sperrpraxis sollte „Roskomnadzor“ dafür sorgen, dass die Netzwerkbetreiber konsequent die Sperrtechnik „IP+URL“ anwenden, um die technisch bedingte Blockierung unbeteiligter Websites zu reduzieren. ${ }^{189}$ Der zu sperrende Inhalt sollte zwecks Rechtssicherheit und Vorhersehbarkeit des Staatshandelns sowie der Verhinderung der "Selbstzensur“ der Netzwerkbetreiber genau bezeichnet werden. Insgesamt sollte die Transparenz der Sperrverfahren in Art. 15.1. InfoG und Art. 15.3. InfoG verbessert werden, indem die Zahl an Registern blockierter InternetRessourcen reduziert und gewöhnlichen Internetnutzern Zugang zu denselben gewährt wird. Auch eine laufende offizielle Statistik über die Sperrpraxis von „Roskomnadzor" wäre wünschenswert. Die staatlichen Internetsperren sollten gezielt und effektiv erfolgen, da die russischen Behörden durch unkontrollierte und am Ende wirkungslose Sperraktionen (wie im Fall von „Telegram“) an Glaubwürdigkeit einbüßen.

Mittelfristig ist in Russland eine weitere Verschärfung der staatlichen Regulierung des Internets zu erwarten, wovon die zahlreichen gesetzgeberischen Vorstöße in diesem Bereich zeugen. ${ }^{190}$ Auch die jüngsten Anpassungen des InfoG im Änderungsgesetz Nr. 472-FZ (zeitliche Straffung des ordentlichen Verfahrens) und dem Änderungsgesetz Nr. 451-FZ (Verzicht auf die Rechtskraft von Gerichtsentscheidungen als Sperrgrundlage) bestätigen diese Tendenz. Die Rolle des Staats im Internet hat sich in Russland in den letzten Jahren grundlegend gewandelt. Während das „Runet“ noch

184 Dazu vorne IV.2.

185 Dazu vorne IV.3.

186 Dazu vorne IV.5.

$187 \mathrm{Zu}$ diesem Fall vorne III.4.b) und zur Unbestimmtheit des InfoG IV.3. und 4.

$188 \mathrm{Zu}$ diesem Fall vorne III.4.c).

189 So auch Чаннов (Ц̌annov), Fn. 18, S. 87.

190 Die Zahl der gesetzgeberischen Vorstöße im Bereich der Internetregulierung stieg von 5 im Jahr 2014 auf 114 im Jahr 2017 an. Dazu Bericht „Agora“, Fn. 94, S. 1, 20. 
vor wenigen Jahren als mehr oder weniger staatsfreie Zone galt, nimmt sich der russische Staat heute mehr und mehr als Garant der moralischen und kulturellen Erziehung der Bürger im Internet wahr. Auch aus der Strategie „Entwicklung der Informationsgesellschaft in der RF für die Jahre 2017-2030"191 ergibt sich die aktive (bevormundende) Rolle des russischen Staates gegenüber den Bürgern bei der Nutzung von Informations- und Kommunikationstechnologien. ${ }^{192}$ In Abschnitt II. Ziff. 19 wird klargestellt, dass die russische Gesellschaft nur an Informationen interessiert sei, welche dem „hohen intellektuellen und kulturellen Entwicklungsstand der Bürger Russlands“ entsprechen, wobei der Staat für sich in Anspruch nimmt, zu entscheiden, welche Informationen dies sind.

191 Указ Президента РФ от 9 мая 2017 г. N 203 „О стратегии развития информационного общества в Российской Федерации на 2017-2030 годы“ (Dekret des Präsidenten der RF vom 9. Mai 2017 Nr. 203 ,über die Strategie Entwicklung der Informationsgesellschaft in der RF für die Jahre 2017-2030“), C3 РФ 2017 N 20 (1 ч.), ст. 2901 (SZRF 2017, Nr. 20, Pos. 2901).

192 In Abschnitt I. Ziff. 3 werden die Priorität der traditionellen russischen geistig-moralischen Wertevorstellungen (Bst. ,B“) und die Gewährleistung des staatlichen Schutzes der Interessen der Bürger in der Informationssphäre (Bst. „,e“) zu Grundsätzen der Informationsstrategie erhoben. 